\title{
Research Paper \\ Understanding the Lived Experiences of Athlete Elderly in COVID-19 Pandemic in Tehran (A Phenomenological Approach)
}

\author{
${ }^{*}$ Rasoul Norouzi Seyed Hosseini ${ }^{1}$
}

1. Department of Physical Education and Sport Sciences, Faculty of Humanities, Tarbiat Modares University, Tehran, Iran.

\begin{tabular}{|c|c|}
\hline $\begin{array}{l}\text { Use your device to scan } \\
\text { and read the article online }\end{array}$ & Chtat On: Norouzi Seved Hosseini R. JUnderstanding the Lived Experiences of Athlete Elderly in COVID-19 Pandemic in \\
\hline 口ifing & $\begin{array}{l}\text { Tehran (A Phenomenological Approach) (Persian)]. Iranian Journal of Ageing. 2021; 16(1):46-61. https://doi.org/10.32598/ } \\
\text { sija.16.1.3000.1 }\end{array}$ \\
\hline arsting & dol'https://doi.org/10.32598/sija.16.1.3000.1 \\
\hline
\end{tabular}

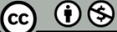

Received: 01 Jul 2020 Accepted: 24 Oct 2020 Available Online: 01 Apr 2021

Key words: Pandemic, Lived experience, Corona, Psychosocial isolation, Older adult's sports

\section{A B S T R A C T}

Objectives Epidemics create extensive socio-behavioral changes in all areas, sport is no exception. The current study aimed at understanding the lived experience of athletic older adults from the Coronavirus Disease 2019 (COVID-19) pandemic.

Methods \& Materials The present qualitative research applied a phenomenological approach. The study participants were 16 athletic older adults in Tehran City, Iran who were selected by the purposive sampling method. Through in-depth and unstructured interviews, the required data were collected. The obtained data were analyzed using the seven-step Diekelman's (1993) approach.

Results According to the obtained data, 4 categories of meanings were identified about the lived experiences of the explored elderly from the COVID-19 pandemic. These categories included the experiences of psychosocial isolation and thinking about death; the marginalization of older adult's sports; mood swings and lifestyle changes, and finding opportunities for sports activism.

Conclusion These concepts of experiences in the life-world of athletic older adults in Tehran from the COVID-19 pandemic were the constitutions of their social action. In the case of proper analysis and application, they can be helpful in better managing professional sports in epidemics.

\section{Extended Abstract}

\section{Introduction}

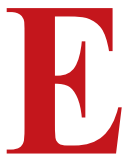

pidemics can cause various socio-behavioral changes, i.e., generated by how they are experienced by individuals [17]. The Coronavirus Disease 2019 (COVID-19) pandemic has greatly altered sports-related interactions (especially the elderly's sports) [12, 15]. Moreover, its main impact on sports environments is the cessation of collective and individual sports activities, and the closure of sports environments [10]. Given the suspension of sports activities for certain segments of society, as well as the high risk of COVID-19 for the elderly, older athletes may have experienced the conditions in a particular way. Therefore, understanding these changes and the meaning of the elderly athlete's experience of the COVID-19 epidemic can provide useful information for such conditions and facilitate older sports policymakers to manage the current specific unstable, uncertain, and complex world.

\section{Methods and Materials}

This qualitative research applied a phenomenological approach. Based on this approach, the researcher sought to interpret and understand the lived experience of the elderly athletes in Tehran City, Iran from the COVID-19 epidemic.

\section{"Corresponding Author:}

Rasoul Norouzi Seyed Hosseini, PhD.

Address: Department of Physical Education and Sport Sciences, Faculty of Humanities, Tarbiat Modares University, Tehran, Iran

Tel: +98 (912) 1867420

E-mail: rasool.norouzi@modares.ac.ir 
The criterion of being an athlete for the elderly (i.e., individuals aged over 60 years living in Tehran) having at least 3 weekly sessions of sports activities was considered regular. The study participants were selected by the purposive sampling method [18]. The study samples were selected with a maximum difference from each other [19]. This is because the purpose of this study was to obtain a range of views of the older athletes about their lived experiences of the COVID-19 pandemic and its interpretation.

In-depth unstructured interviews were used to collect the necessary data. In the present study, the researcher has interviewed 16 elderly Iranian athletes from March 11, 2019 , to May 20, 2020. Each interview lasted 45-60 minutes. At the beginning of the interview, a few general open-ended questions were asked (What did you experience about the COVID-19 pandemic? What aspects in your life influenced your experience of the COVID-19 pandemic?).

The phenomenological approach in this study was interpretive; therefore, to interpret and analyze the relevant data, the approach of Dickelman et al. [21] was used. After the interview, the recorded words were transcribed, and the sentences, phrases, and quotations that indicated the study subjects' understanding of the phenomenon were identified. Next, the researcher used important phrases to categorize the meanings and concepts that led to the achievement of sub-themes. These sub-themes were also used to write what the study participants have experienced in covering the main themes. To ensure the reliability of the obtained information ${ }^{3}$, the research participants were referred and their compliance with the interpretations was ensured. The current study was approved by the specialized committee of the Department of Sports Sciences (as a local ethics committee) at Tarbiat Modares University.

\section{Results}

Based on the data analysis, 4 main themes of the lived experiences of the examined elderly from the COVID-19 pandemic were obtained, i.e., interpreted as follows:

\section{The experience of increasing psychosocial isolation and mortality}

One of the most essential and frequent sub-themes of this main theme was ignoring and increasing the restrictions on sports participation for elderly athletes. The examined elderly stated that they were ignored by the authorities in their plans and measures regarding sports and physical activity; accordingly, this issue imposed a great psychological burden on them. As per participant No. 3, "As much as I follow the news, I see that they do not mention anything about senior sports; it is all about professional athletes and the resumption of leagues." This neglect of the elderly and their exercise has caused them psychological stress and isolation. The feeling of depression and consequently the reduction of opportunities for sports participation was repeatedly expressed among the research samples; thus, such conditions led them to psychosocial isolation.

\section{The marginalization of old age sports}

Regarding the marginalization of senior sports during the COVID-19 epidemic, the study participants stated that the authorities neglect senior sports and overlook the health needs and requirements for older athletes in their reopening policies.

\section{Unwanted changes in lifestyle and mood disorders}

This was one of the most frequently discussed topics by the explored subjects. They stated that during the COVID-19 pandemic, they developed obsessive-compulsive disorder, mood swings, insomnia, and dietary changes; ultimately, they presented weakness and physical problems. Living conditions in quarantine and socio-physical distancing have led to the disruption of the lifestyle and the routine of the elderly athletes; consequently, this lifestyle change has affected their moods.

\section{Active and creative sports activism}

According to this theme, some of the studied elderly attempted to accept the existing conditions and adapt to them as much as possible and take advantage of the existing opportunities. Older athletes tended to act as active elements at different levels in the current situation. This has led some of their creativity to emerge and design their exercises in their quarantine environments. "I designed a series of exercises with small sticks that I could do at home", mentioned participant No. 3. The invention of new sports and body movements by the elderly was among the sub-themes of active and creative sports activism.

\section{Discussion and Conclusion}

The explored elderly have experienced the COVID-19 epidemic with unintended lifestyle alternation and mood swings. Special conditions and health requirements have caused their moods to fluctuate and their lifestyles to change. Ignorance and high sensitivity, along with increasing restrictions on participation in sports, have made them more fearful of death; subsequently, this condition creates an experience of psychosocial isolation and death thinking in the examined older athletes. Improper compassion and indifference of of- 
ficials to the needs of the sports of the elderly; disregarding the requirements of reopening sports facilities for the elderly; as well as the loss of expression have made the elderly athletes prone to the experience of marginalizing senior sports. Additionally, some older athletes have attempted to adapt to the new conditions and develop creativity to have the desired physical activity. They have experienced active and creative activism in sports, resulting from the transformation of threats into opportunities and the acceptance of a lifestyle in the context of the COVID-19 pandemic.

\section{Ethical Considerations}

\section{Compliance with ethical guidelines}

This study was approved by the Ethics Committee of the Department of Sports Science, Tarbiat Modares University. All ethical principles are considered in this article. The participants were informed about the purpose of the research and its implementation stages. They were also assured about the confidentiality of their information and were free to leave the study whenever they wished, and if desired, the research results would be available to them. The Helsinki declaration (Ethical principles in medical research on humans) was also observed.

Funding

This research was supported by the research project Funded by the Tarbiat Modares University.

Authors' contributions

All authors equally contributed to preparing this article.

Conflicts of interest

The authors declared no conflicts of interest. 


\title{
سالمندان ورزشكار و همهيَيرى كوويد 19: واكاوى تجربه زيسته سالمندان ورزشكار تهرانى

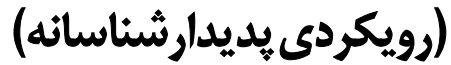

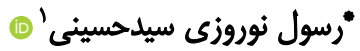

1. كروه تربيتبلنى و علوم ورزشى، دانشكده علوم انسانى، دانشكاه تربيت مدرس، تهران، ايران.

\begin{abstract}
حكSי

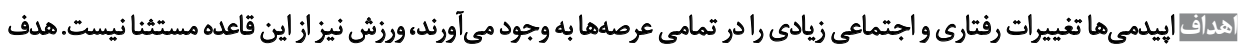

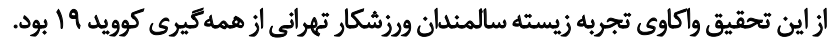

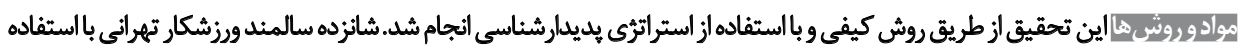

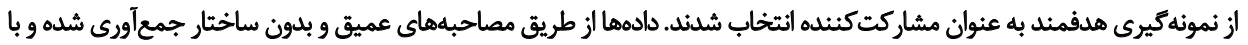

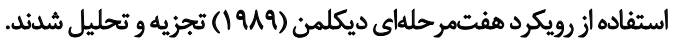

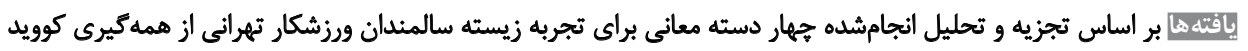

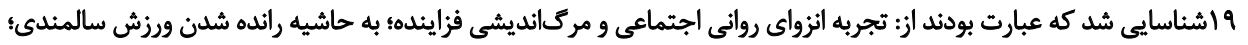

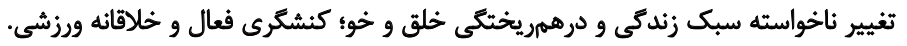

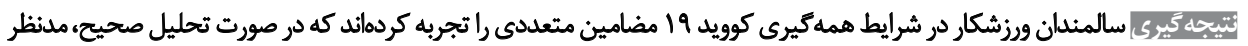

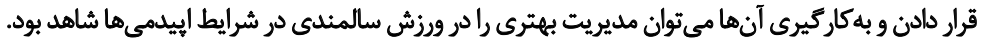

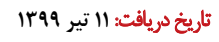

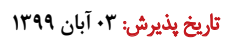

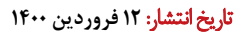

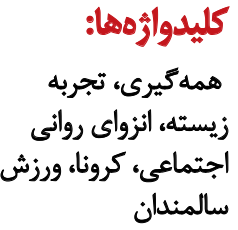

[ه]]. از يَيامدهاي مطلوب مشاركت ورزشى براي سالمندان بهبود

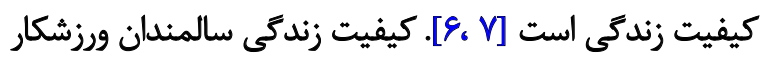

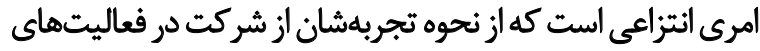

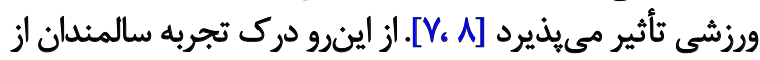

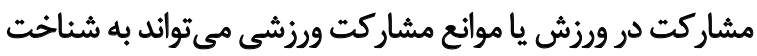

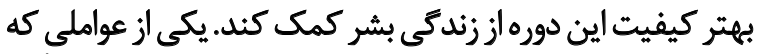

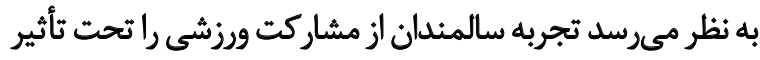

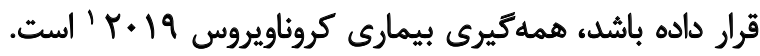

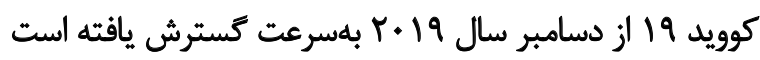

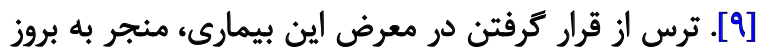

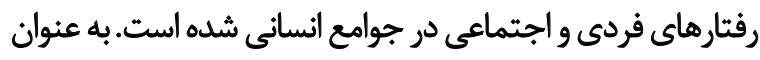

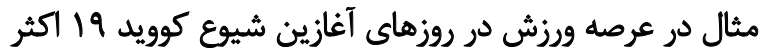

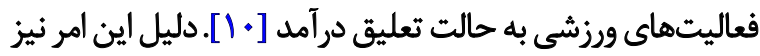

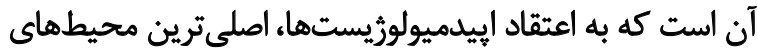

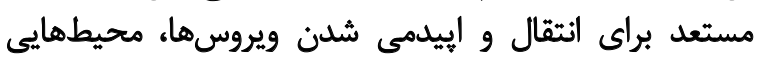

doles

سالمندى دوران حساسى از زندگى بشر است و توجه به مسائل

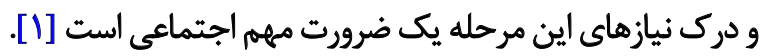

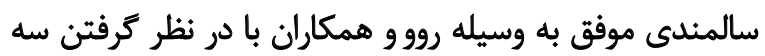

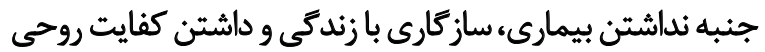

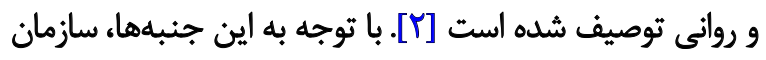

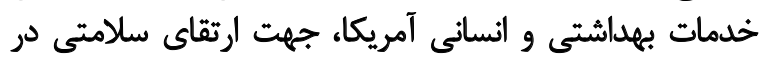

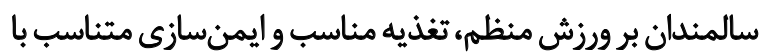

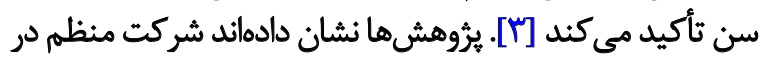

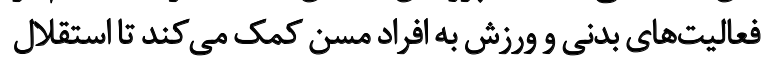

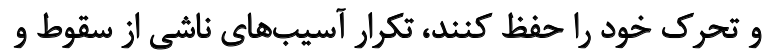

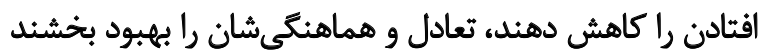

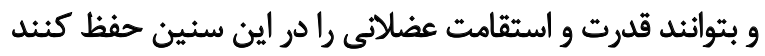

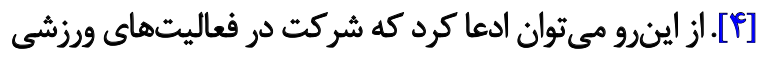

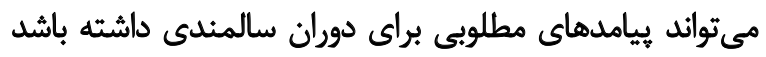




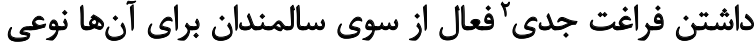

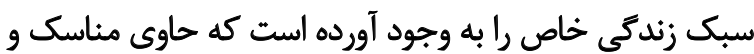

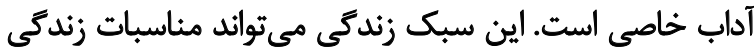

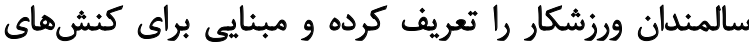

اجتماعى آنها باشد [19]

بديده همهيرى كوويد 19 به ميزان بسيار زيادى مناسبات

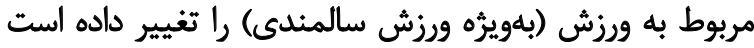

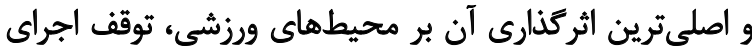

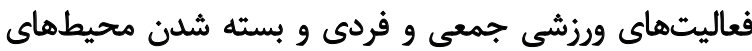

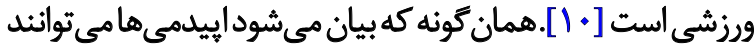

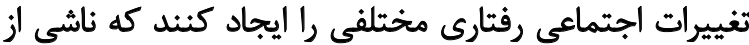

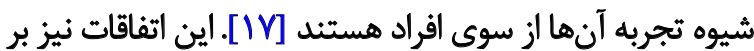

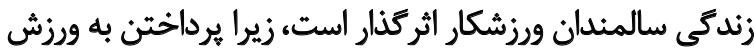

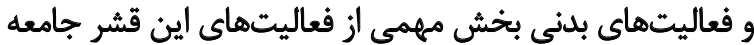

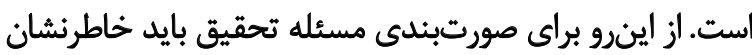

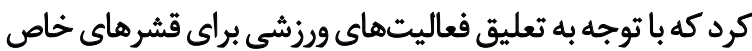

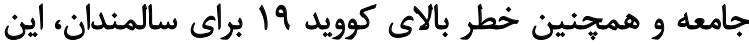

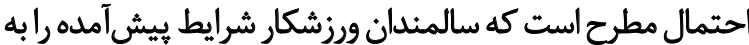

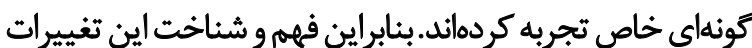

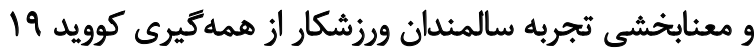

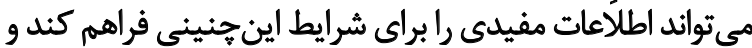

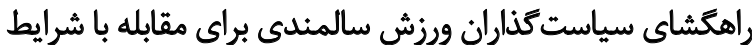

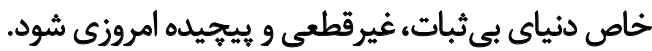

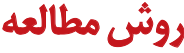

اين تحقيق با روش كيفى و از طريق استراتثرى بديدارشئاسى إنى

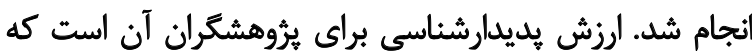

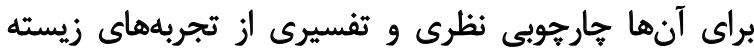

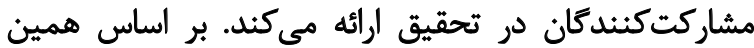

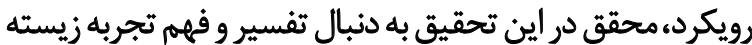

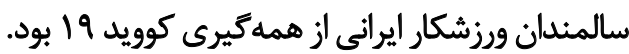

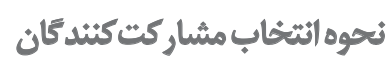

جامعه موردمطالعه در اين برؤهش شامل تمامى سالمندانى بود

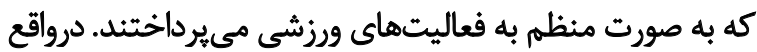

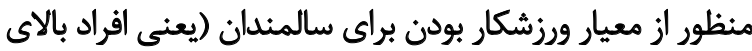

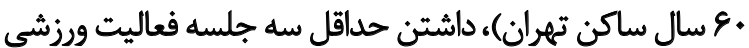

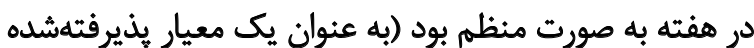

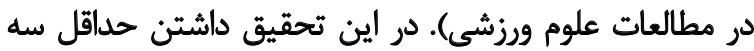

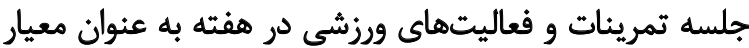

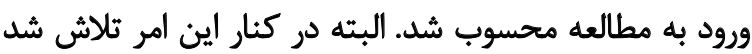
سابقه ورزشى افراد نيز مورد بررسى قرار كيرد و كسانى كه دارئي
هستند كه تعاملات بدنى دِر آنها بالاست [11] كه اين ويرَّى در عرصههاى ورزشى كاملاً مشهود است.

شرايط بهوجودآمده و تعليق فعاليتهاى ورزشى منجر به به به به

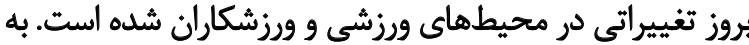

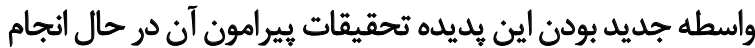

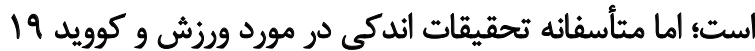

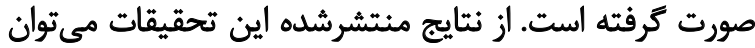

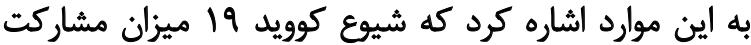

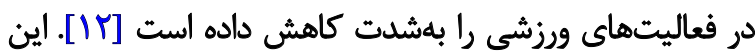

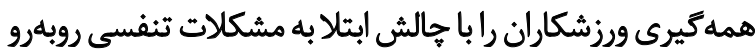

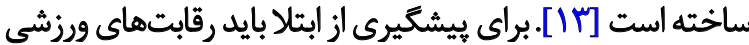

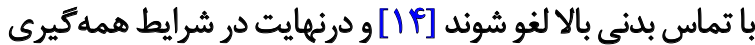

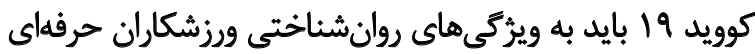

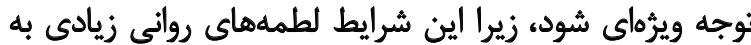

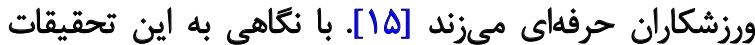

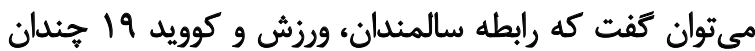

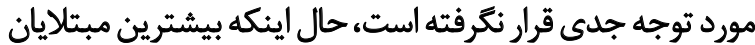

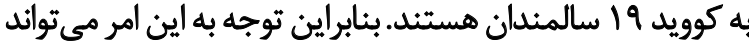

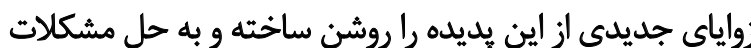

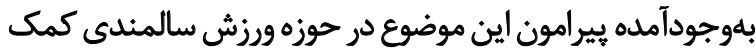
Sis

بر اساس كزارشهاي منتشرشده، اولين نمونههاي مبتلا به

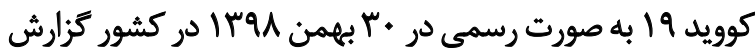

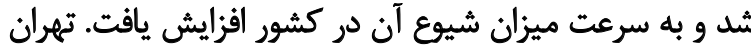

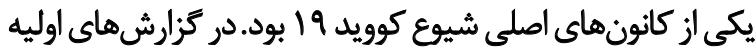

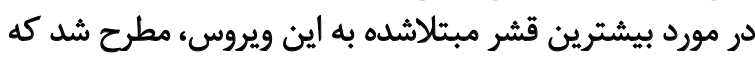

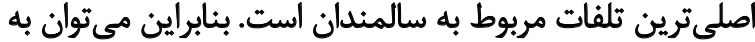

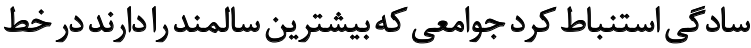

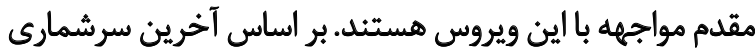

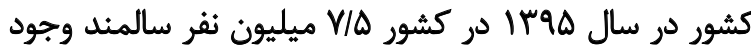

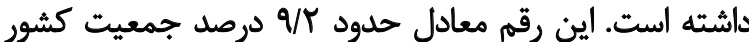

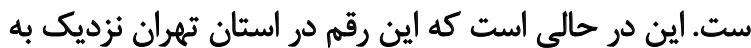

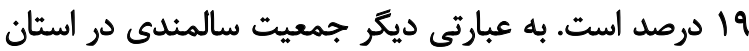

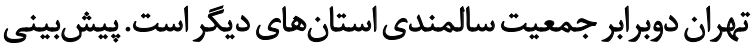

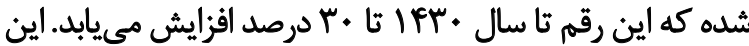

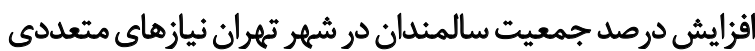

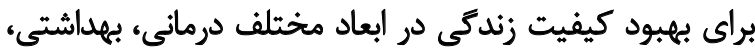

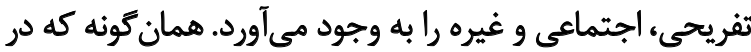

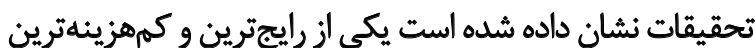

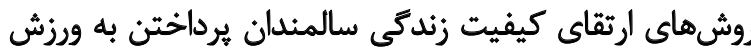

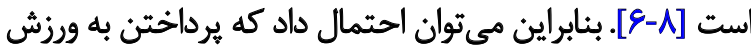

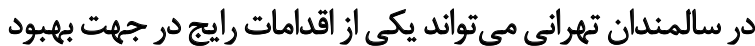

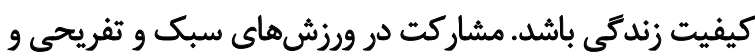


با خلاصهسازى آن جيزى كه در مورد آن تجربه، شنيده بود و

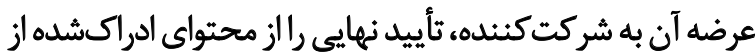

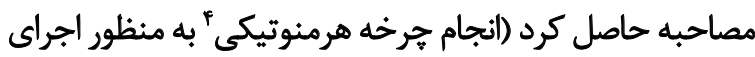

$$
\text { يديدارشناسى تفسيرى). }
$$

بيش از اجراى مصاحبهها، يك مصاحبه به تعليق درآوردن

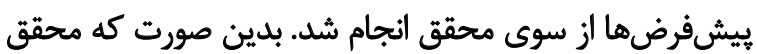

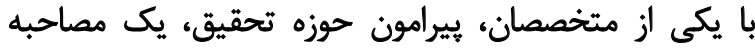

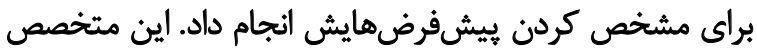

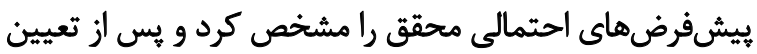

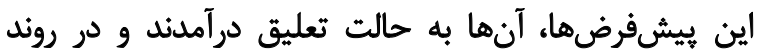

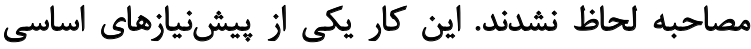

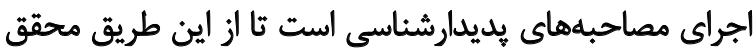

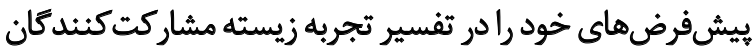

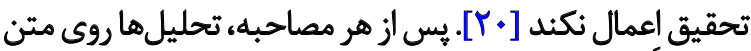

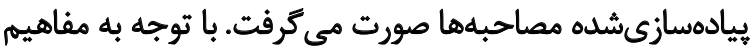

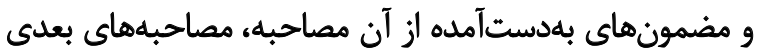

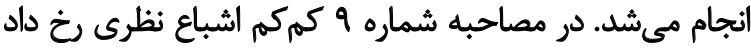

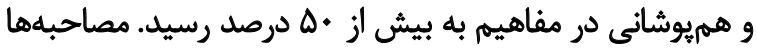

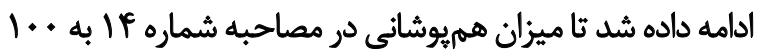

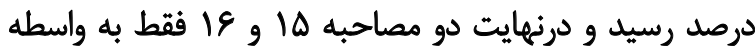

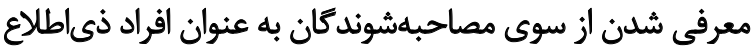

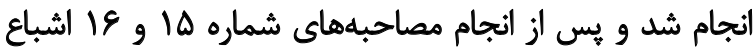

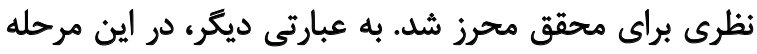

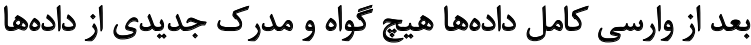

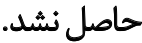

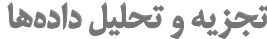

از آنجايي كه رويكرد بديدارشناسى در اين تحقيق به شكل تهل تهلي

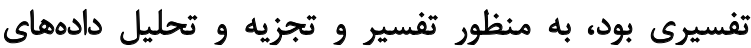

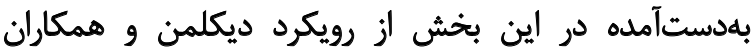

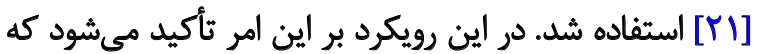

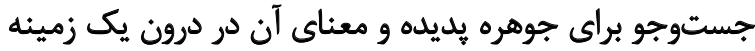

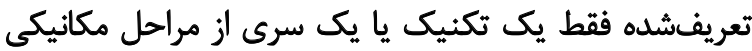

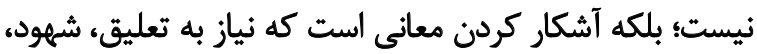

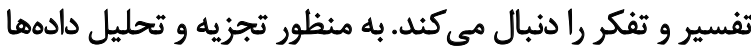
فرايند هفتمر حلهاى زير انجام شد:

ا. تمامى مصاحبهها براى دريافت ايده كلى (معناى تجربه زيسته) رونويسى و خوانده شدند.

r. خلاصههاى تفسيرى نوشته شد و جستوجوهايى براى

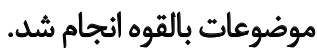

r. نوار بيادهده از مصاحبهها به مثابه يك كار كروهى براى
بيشينه ورزشى (از قبيل عضويت در تيمهاى ورزشى يا داشتن

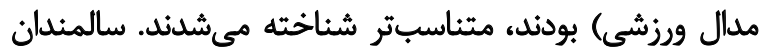

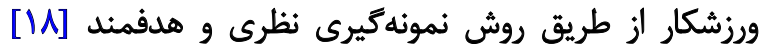

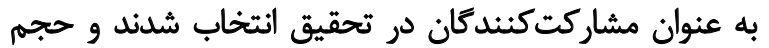

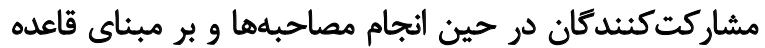

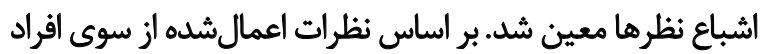

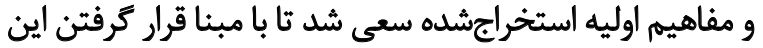

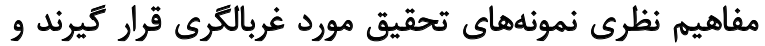

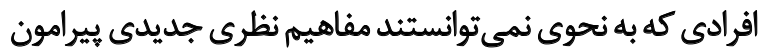

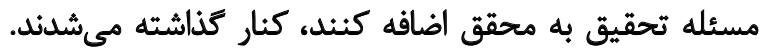

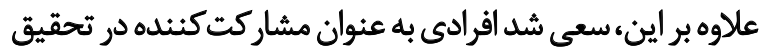

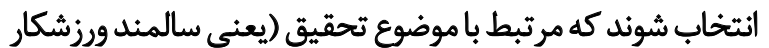

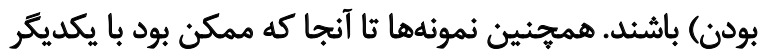

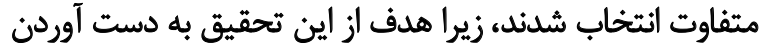

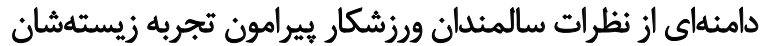

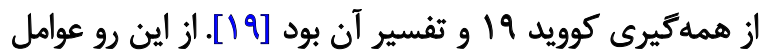

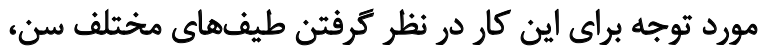

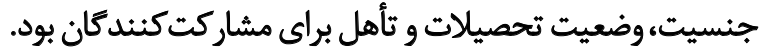

\section{فرايثد جمعآورى دادهها و اجراى مصاحبه}

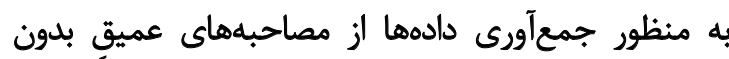

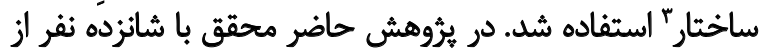

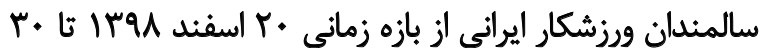

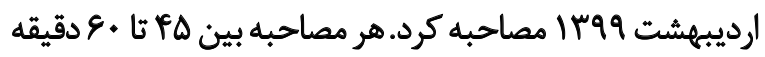

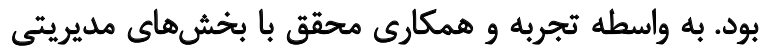

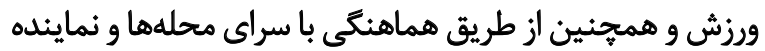

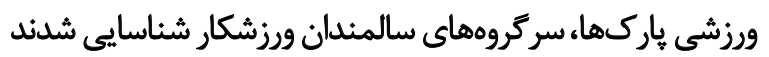

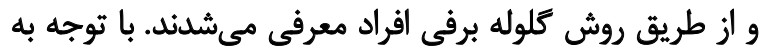

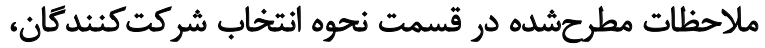

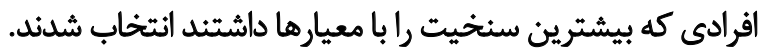

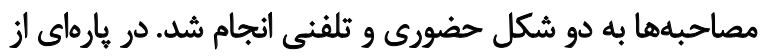

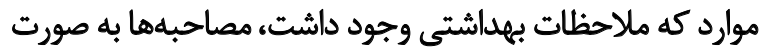

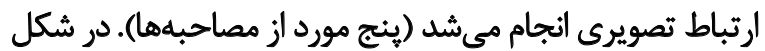

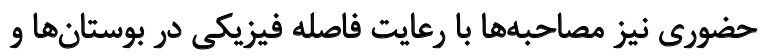
ميدانهاى ورزشى عاركها انجام شد (يازده مورد).

در اين مصاحبهها هدف محقق نفوذ به لايههاى عميق ذهن

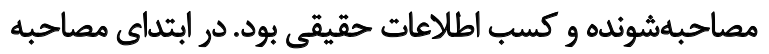

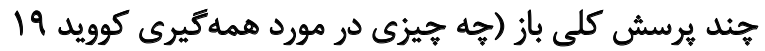

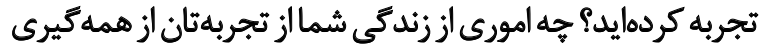

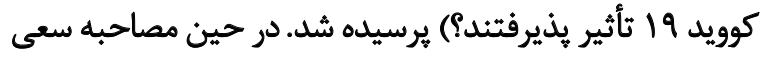

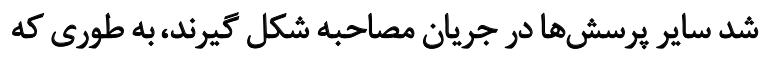

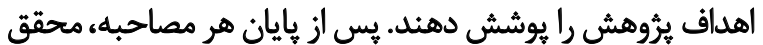


محقق بود كه تا حد امكان اطلاعات زيادى را بيرامون روش

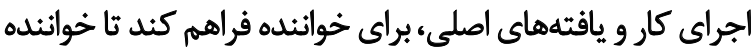

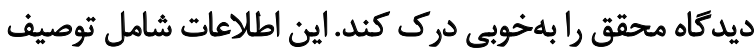

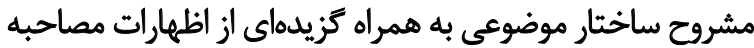

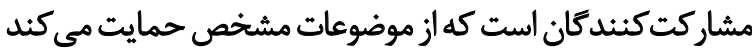

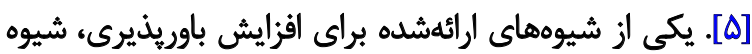

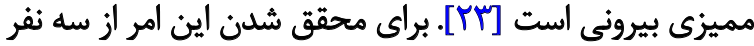

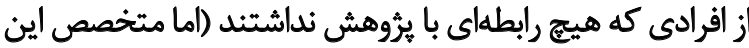

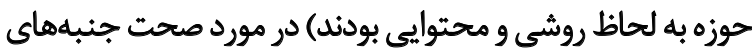

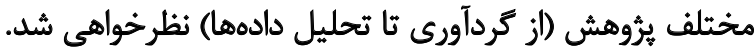

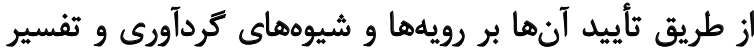

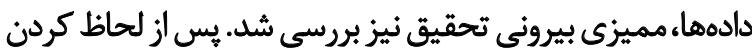

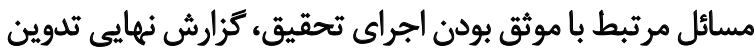

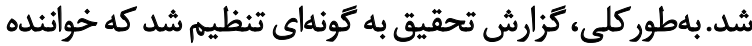

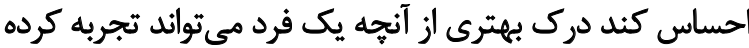

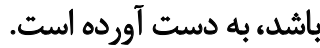

يافتهها

درمجموع، شانزده مصاحبه با سالمندان انجام شد كه

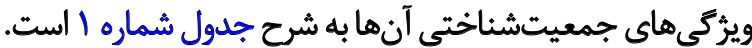
بر اساس رويههاي مطرحشده در قسمت روششيناسى و طبقهبندى دادهها، مفاهيم و مضامين فرعى و اصلى بـ به شرح

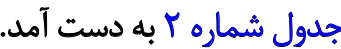

بر اساس تحليل دادهها جهار مضمون اصلى از تجربه زيسته

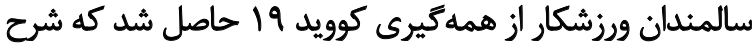
تفسيرى آنها به صورت ذيل است أني كوري

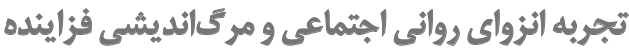

يكى از مضامين اصلى استخراجشده كه به طور مكرر در

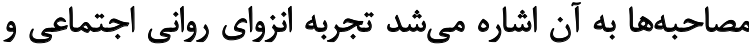

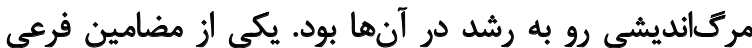

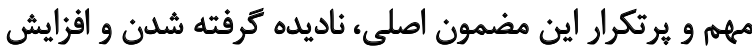

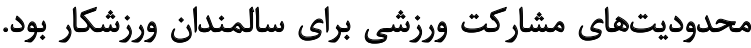

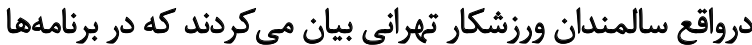

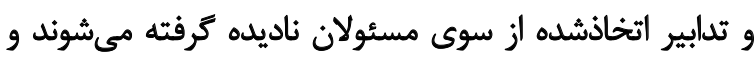

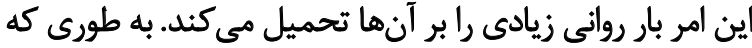

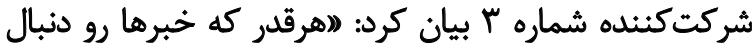

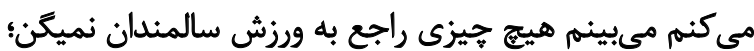

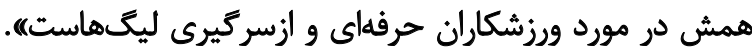

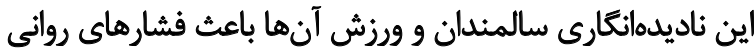

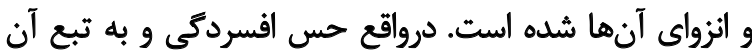

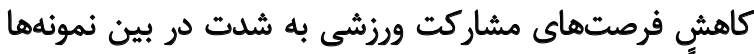

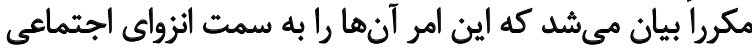

يك موضوع تفسيرى بررسى شد.

fأ. به متن و همجنين مشاركت كنيندكان براى روشن كردن مضامين فرعى و اصلى مجدداً مراجعه شد شد.

هـ متون براى تعيين معانى رايج و اعمال مشترك مورد مقايسه

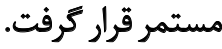

ع. الكوهاى مرتبط با موضوعات تعيين شدند.

V. از كروه مفسران و ساير همكاران براى بيشنهادها در طرح

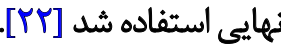

آزبه بيان ساده يس از اجراي مصاحبه، سخنان ضبطشده توسط

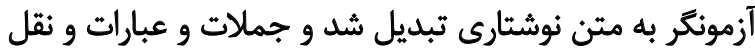

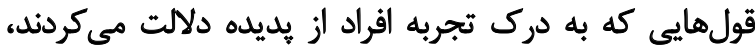

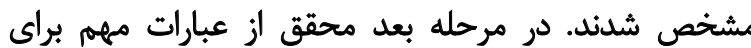

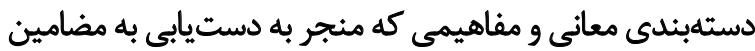

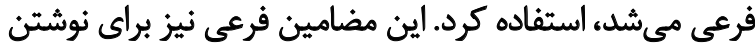

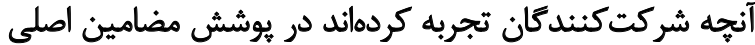

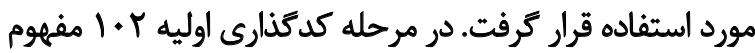

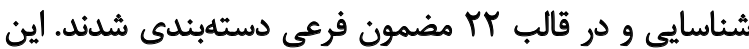

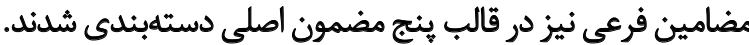

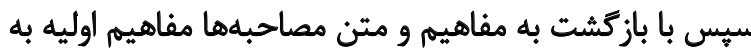

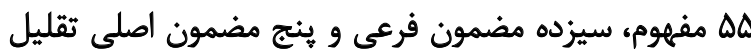

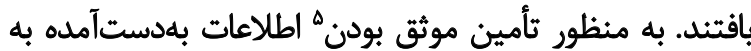

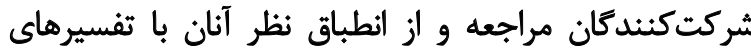

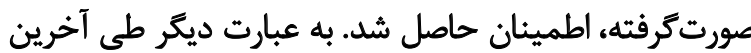

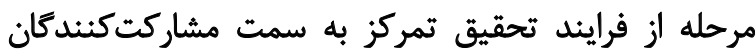

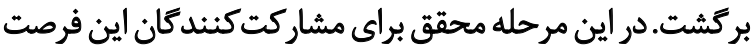

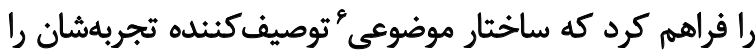

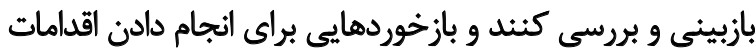

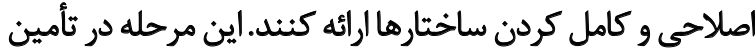

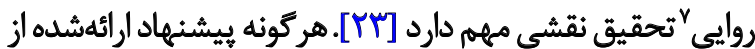

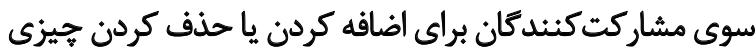

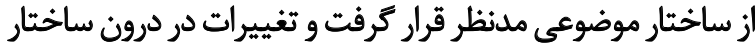

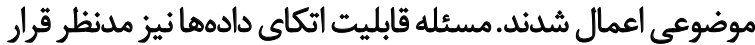

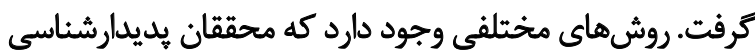

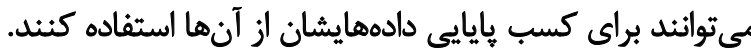

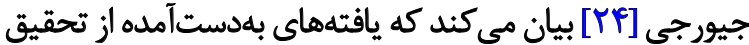

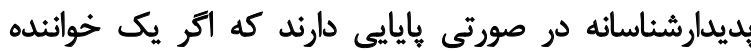

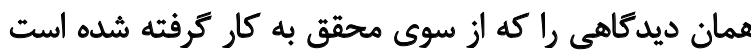

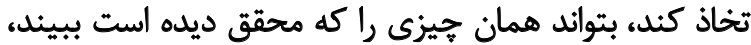

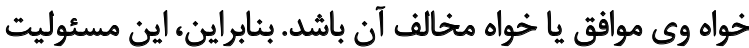

5. Trustworthiness

6. Thematic structure 7. Validity 
جدول ا. ويرُكى هاى جمعيتشُناختى مشاركت كثندكان در تحقيق

\begin{tabular}{|c|c|c|}
\hline تعداد & دسته & متغير \\
\hline v & بين .عتا هو & \multirow{5}{*}{ سن (سال) } \\
\hline$\Delta$ & 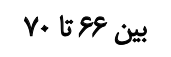 & \\
\hline r & بين Votrit & \\
\hline r & 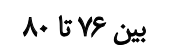 & \\
\hline 1 & بالآتر از ا 1 & \\
\hline 11 & مثأهل & \multirow{3}{*}{ وضعيت تأهل } \\
\hline i & بيوه & \\
\hline 1 & هجرد & \\
\hline$\wedge$ & دييلم و إيايينتر & \multirow{4}{*}{ تحصيلات } \\
\hline$\Delta$ & كارشناسى & \\
\hline r & كارشناسى ارشد & \\
\hline 1 & دكترى & \\
\hline 8 & زن & \multirow{2}{*}{ جنسيت } \\
\hline 1. & هرد & \\
\hline 18 & تهران & هحل سكونت \\
\hline is & \multicolumn{2}{|c|}{ جمع كل } \\
\hline
\end{tabular}

L

بيارم)؛؛ يا شركت كننده شماره ل ل بيان كرد: (ابا اينكه بيست ساله

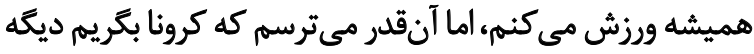

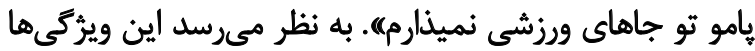

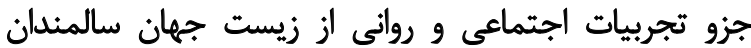

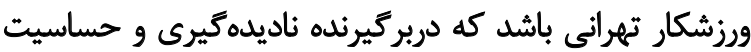

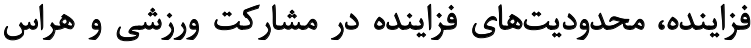

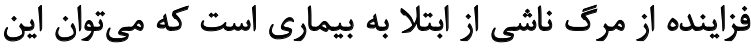

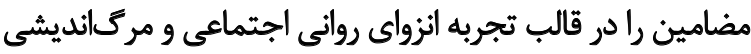

فزاينده از شرايط همدكيرى كوويد 19 انفسير كردي اجنمي به حاشيه رائده شدن ورؤش سالمثدى

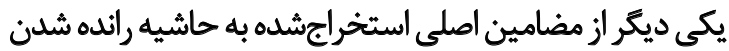

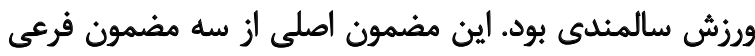

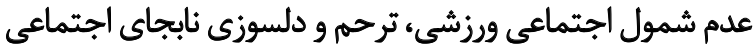

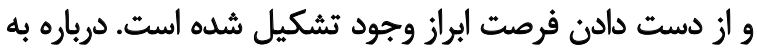

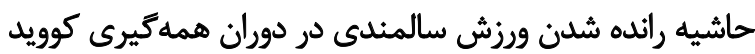

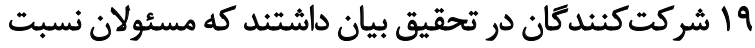

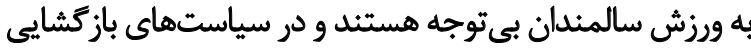

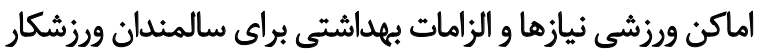

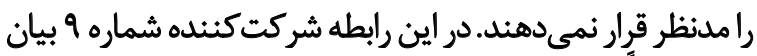

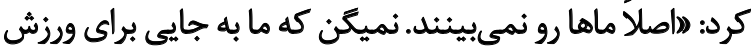

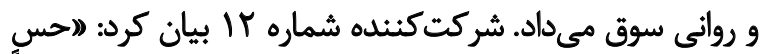

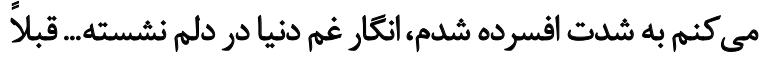

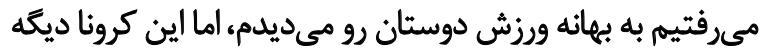

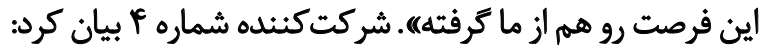

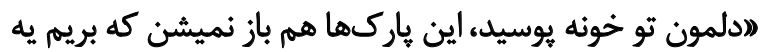

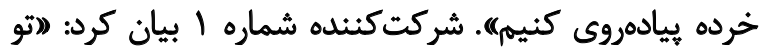

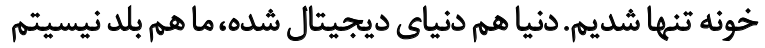

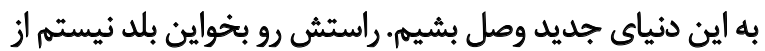

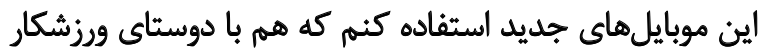

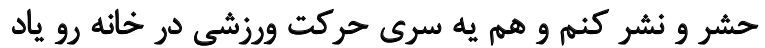

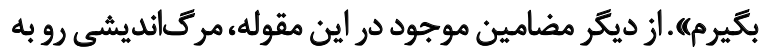

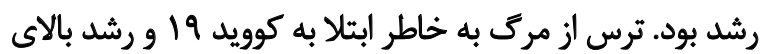

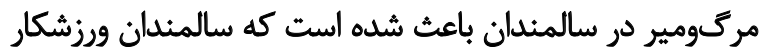

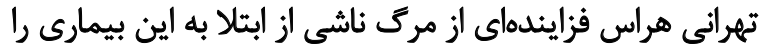

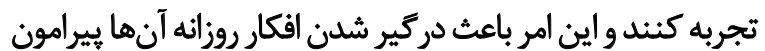

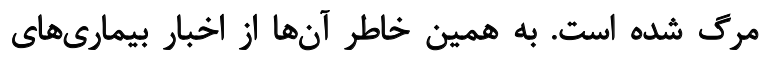

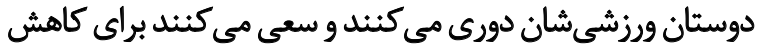

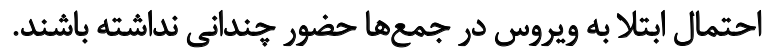

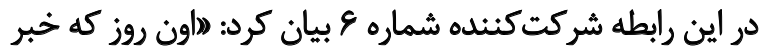

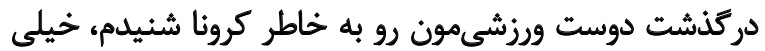

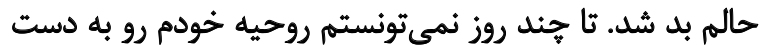


جدول r. مفاهيه، مضامين اصلى و فرعى استخراجشده از تجربيات سالمندان ورزشكار در دوران همهيرى كوويد 19

\begin{tabular}{|c|c|c|}
\hline مفاهيم & مضامين فرعى & مضامين اصلي \\
\hline 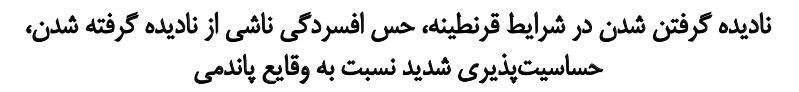 & ناديلدكيرى و حساسيت فزاينده & \\
\hline 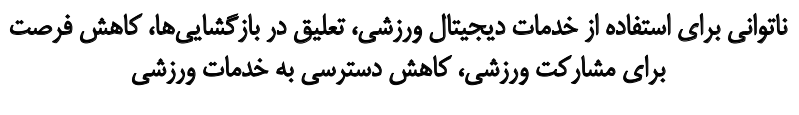 & محدوديت فزاينده در فرصتهاى مشار & تجربه انزواي روانى اجتماعى و \\
\hline 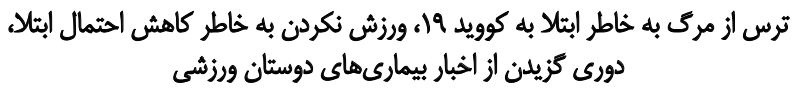 & هراس فزاينده از مرى ناشى از & \\
\hline 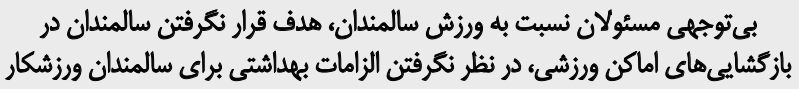 & عدم شمول اجتماعى ورزشى & \\
\hline 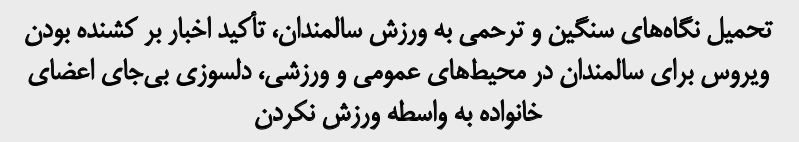 & ترحم و دلسوزى نابجاي & به حاشيه رانده شلن ورزش سالمندى \\
\hline 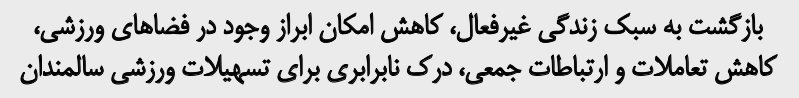 & از دست دادن فرصت ابراز وجود & \\
\hline 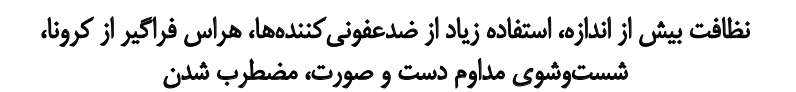 & وسواس نظافت و اضطراب & \\
\hline
\end{tabular}

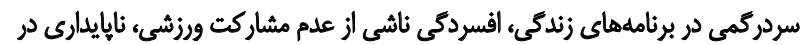

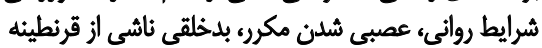

نوسائات خلقى

تغيير ساعات خوابه بيدار ماندن در شبها، يرخورى، بلخورى، خواب بي كيفيت، رعايت

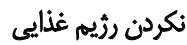

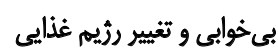

تغيير ناخواسته سبك زندكى و ورئي درهمريختكى خلقوخو زنلوكي

بيىتحركى و عوارض ناخواسته، كاهش آمادكى بلثئ ضعف عضلاثي، مشكلات مفصلى

ضعف و مشكلات جسماني

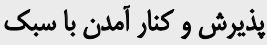

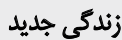

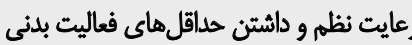

تبديل تهلديدها به فرصتهاي

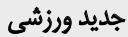
كنشكرى فعال و خلاقانه ورزشى

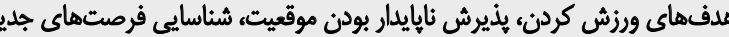

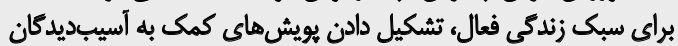

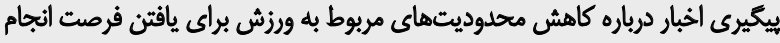

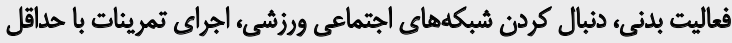

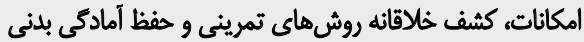

بروز خلاقيت و ابداع ورزشها در هحيط خائه 
شرايط زندكى در قرنطينه و فاصله كذارى اجتماعى فيزيكى منجر

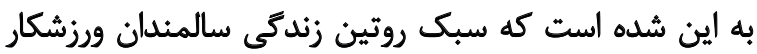

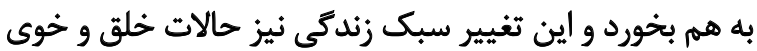

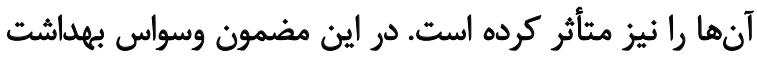

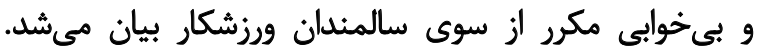

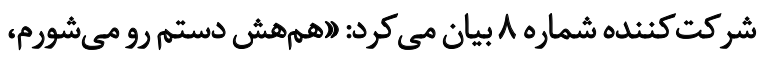

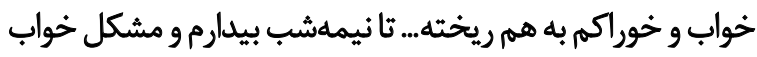

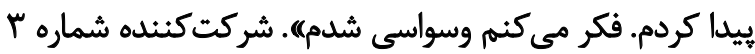

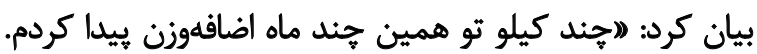

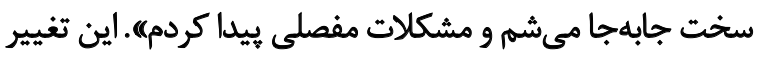

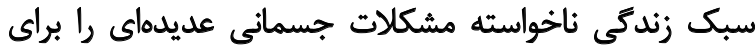

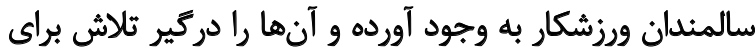

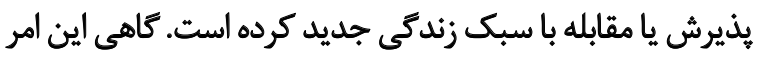

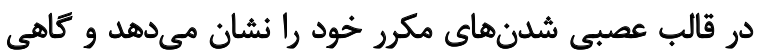

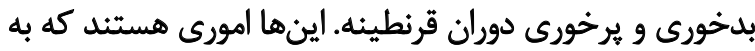

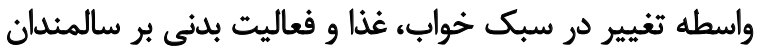

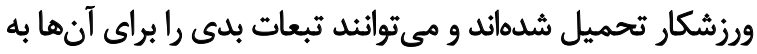

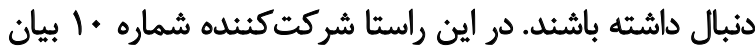

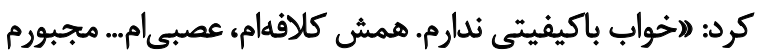

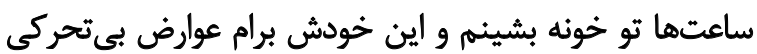

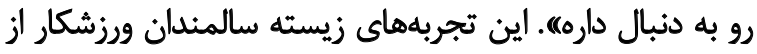

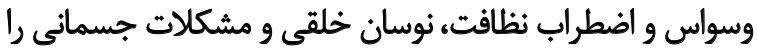

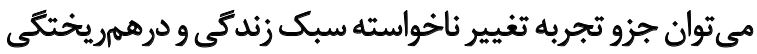

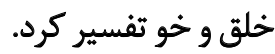

\section{كئشكرى فعال و خلاقانه وروشى تحى}

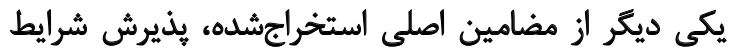

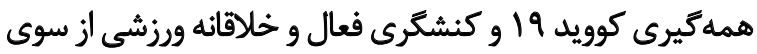

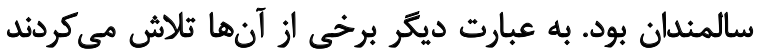

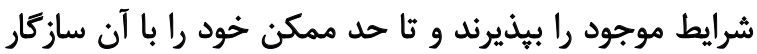

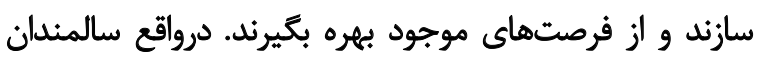

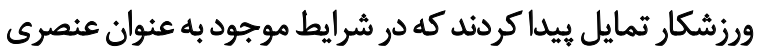

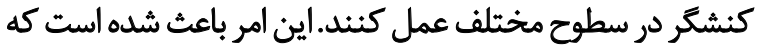

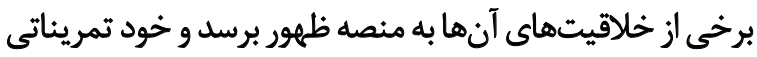

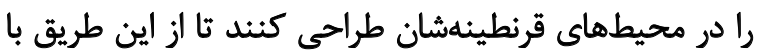

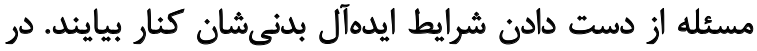

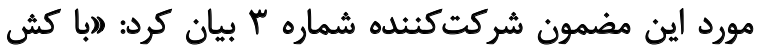

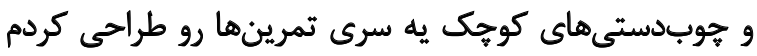

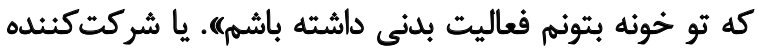

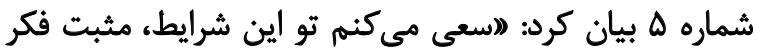

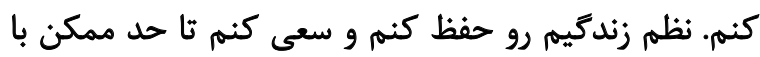

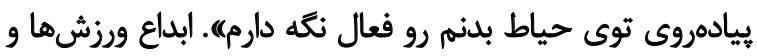
حركات بدنى جديد از سوى سالمندان يكى ازئ از مضامين فرعي

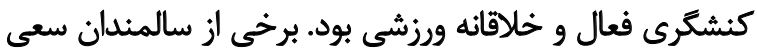

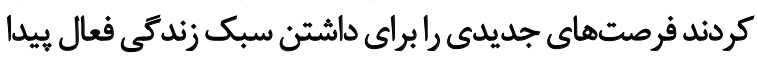

كردن نياز داريم كه بهداشتى و سالم باشه. ما اولويت ورزش كشور

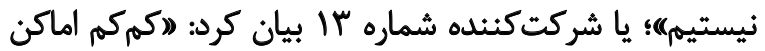

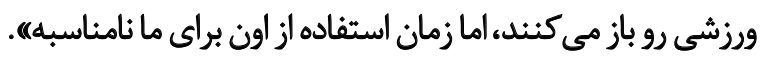

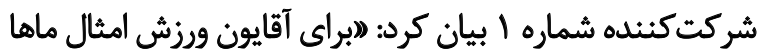

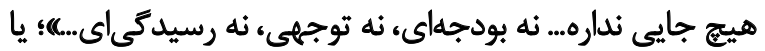

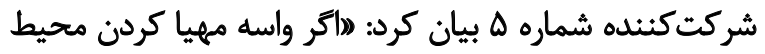

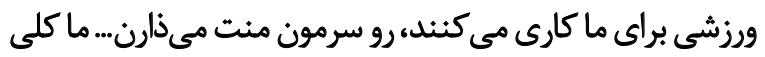

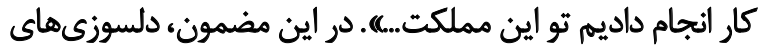

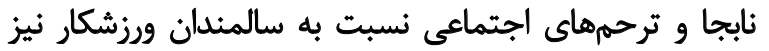

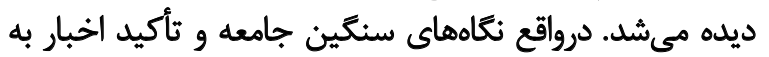

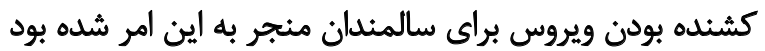

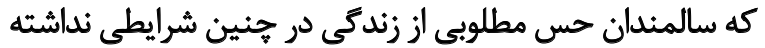

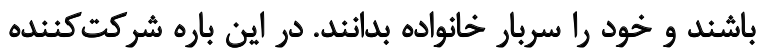

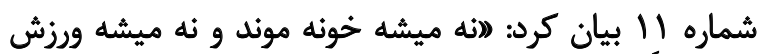

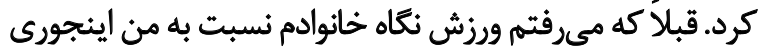

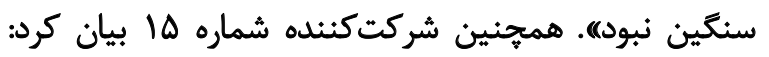

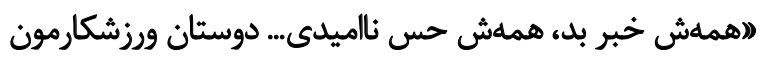

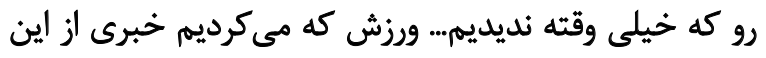
حس و حال نبود. سركرم بوديمها.

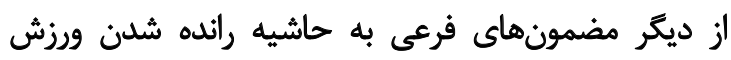

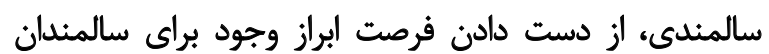

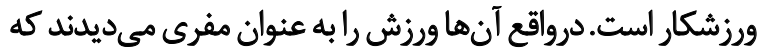

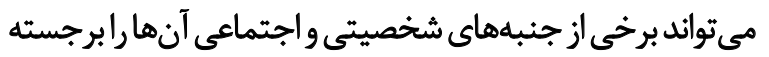

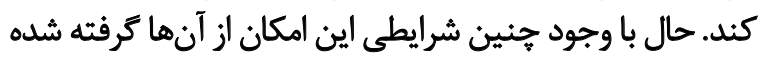

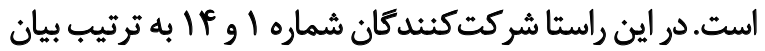

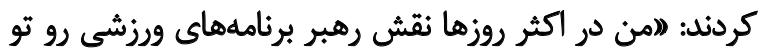

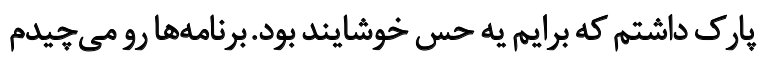

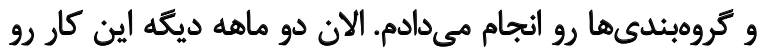

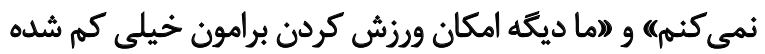

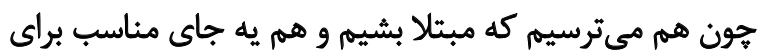

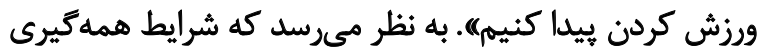

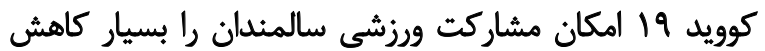

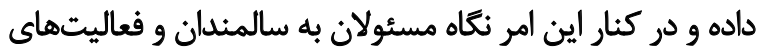

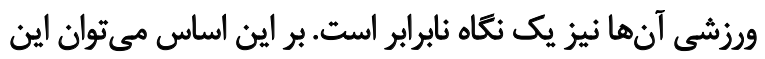

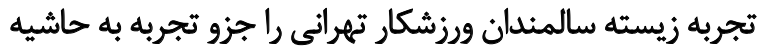
رانده شدن ورزش سالمندى تفسير كرد.

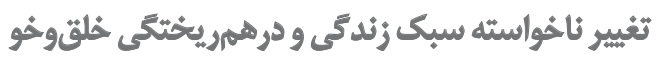
يكي ديكر از مضامين اصلى استخراجشده تغيير ناخواسته

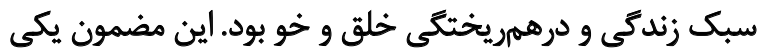

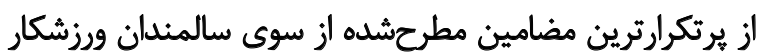

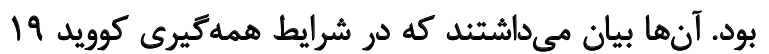

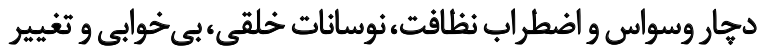

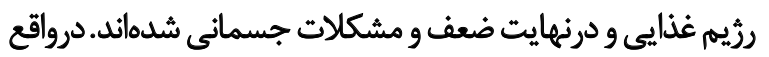


مهمهترين تغييرات رفتارى تجربهشده براى سالمندان ورزشكار در

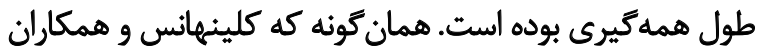

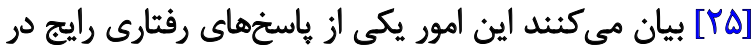

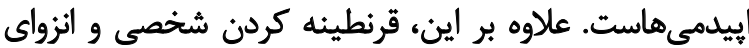

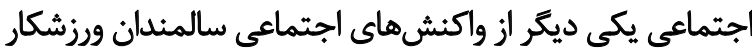

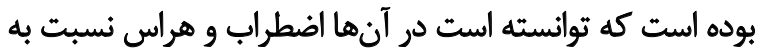

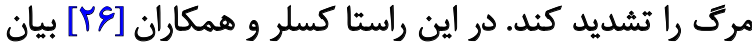

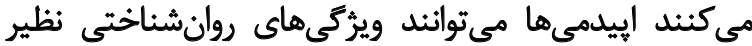

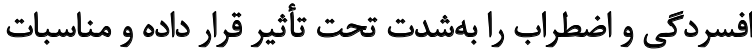

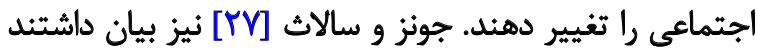

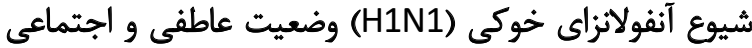

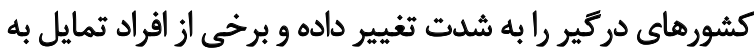

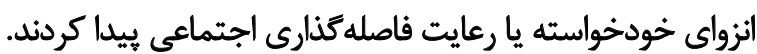

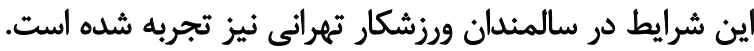

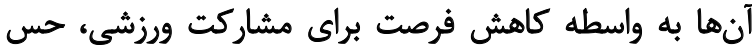

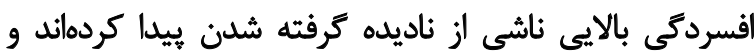

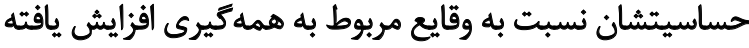

يكى ديكر از مضامين كشفشده به حاشيه رانده شدن ورزش

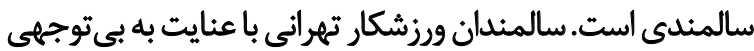

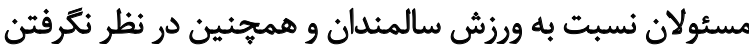

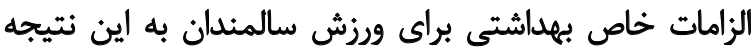

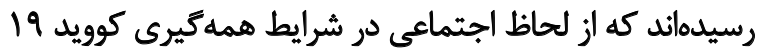

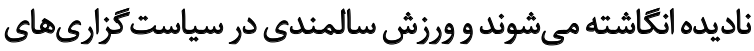

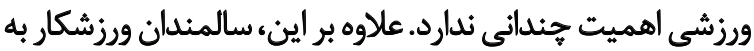

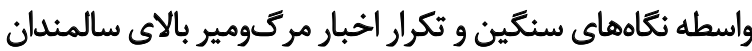

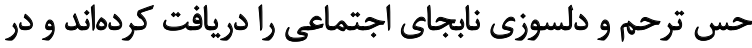

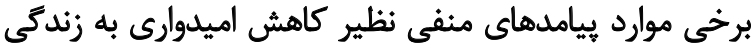

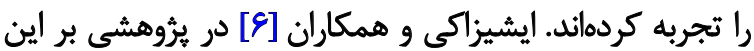

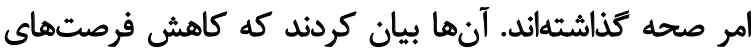

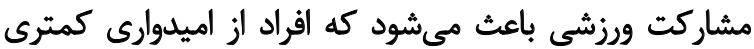

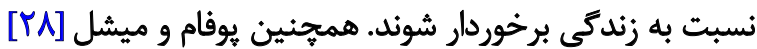

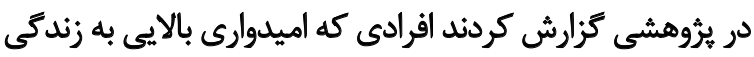

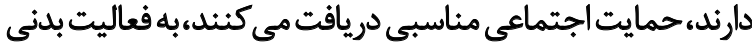

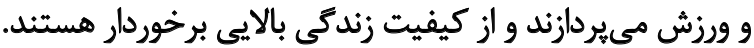

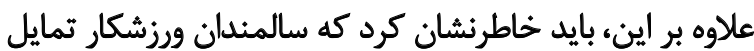

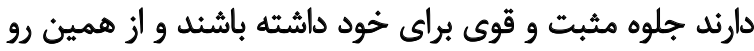

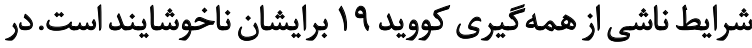

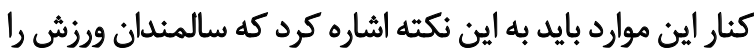

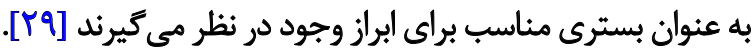

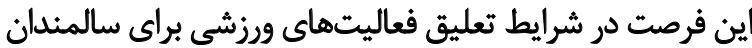

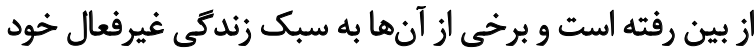

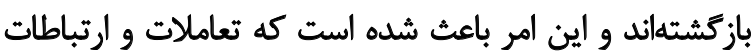
ورزشى آنها كاسته شود و به اين نتيجه برسند كه تسهيل تهريلات
كنيند و با بهرهگيرى از فرصتهاى موجود ميزان آمادتى بدنى شئى

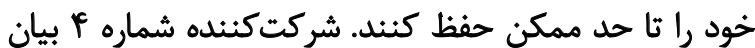

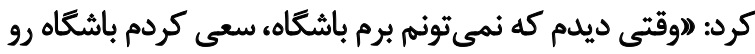

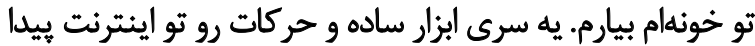

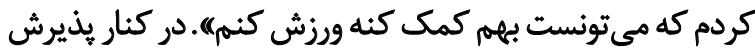

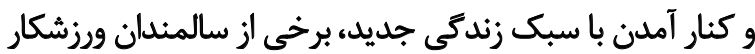

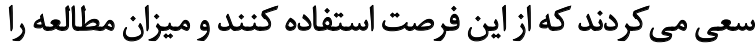

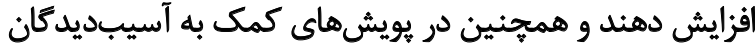
كمك كنئد. شركت كننده شماره

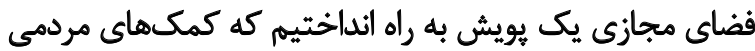

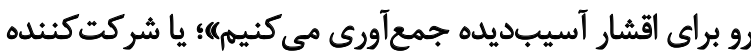

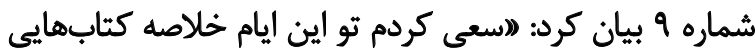

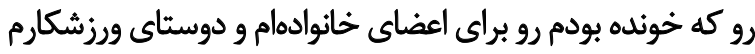

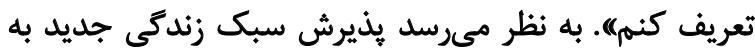

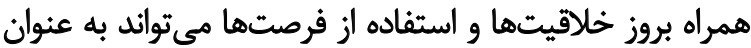

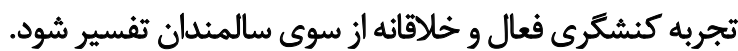

بحث

تحقيق حاضر با هدف درك تجربه زيسته سالمندان ورزشكار

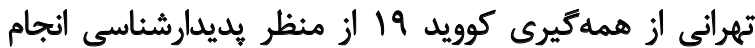

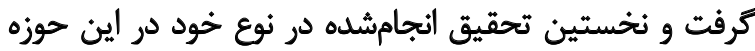

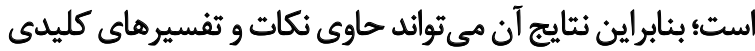

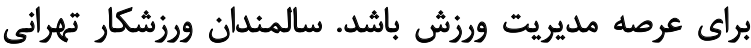

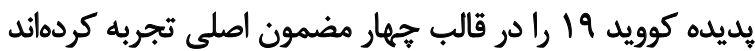

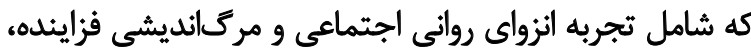

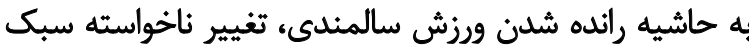

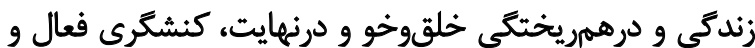
خلاقانه ورزشي هستيند.

مضمون تجربه انزواى روانى اجتماعى و مركانديشى فزاينده

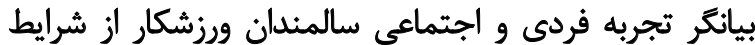

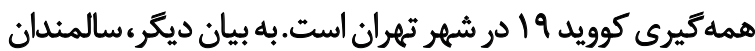

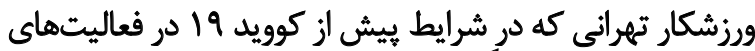

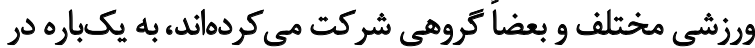

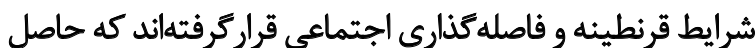
آن كاهش تعاملات اجتماعى و تقويت حس انزئ انزوا براى آنها آنها شده

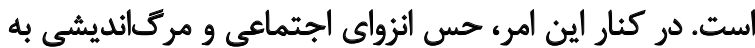

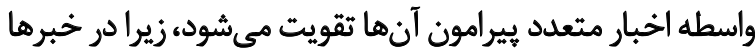

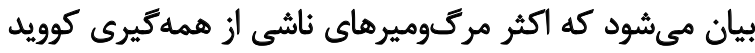

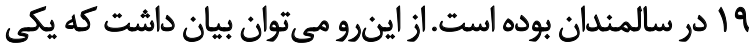

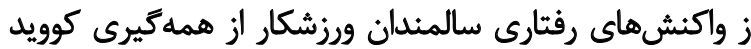

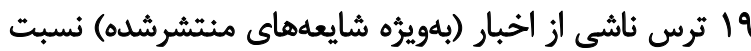

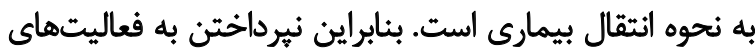

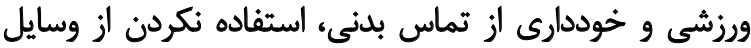

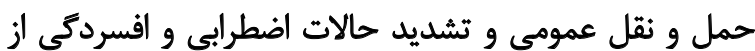




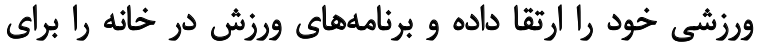

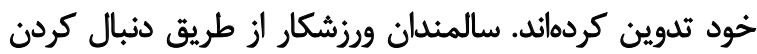

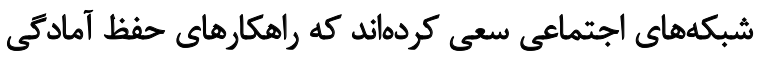

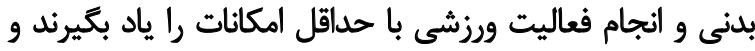

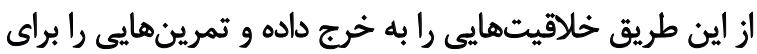

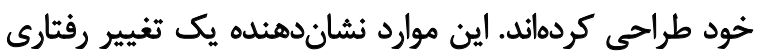

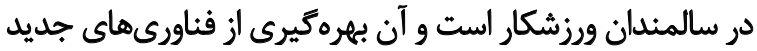

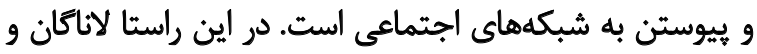

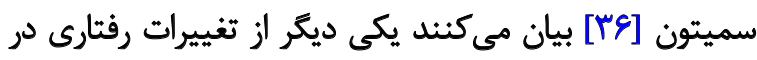

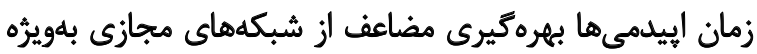

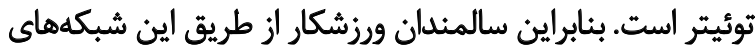

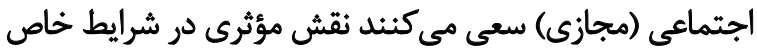

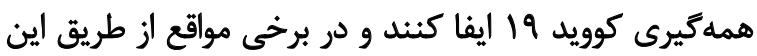
بسترهاي مجازى در فعاليتهاي خيرخي

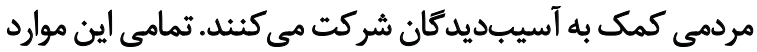

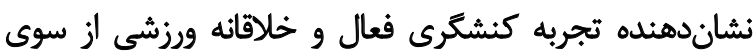

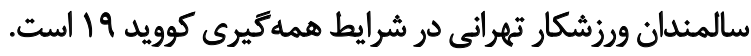

\section{نتيجلكيرى نهايى}

براى نتيجه

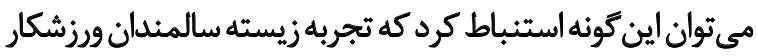

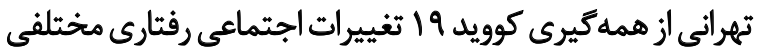

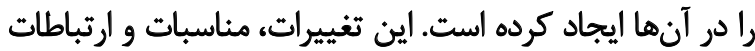

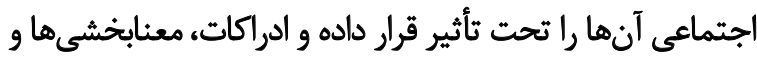

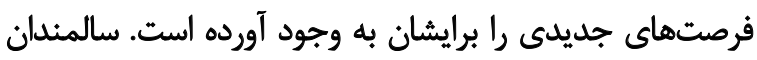

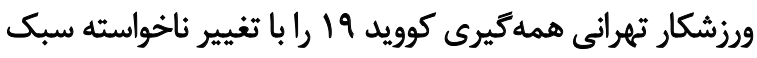

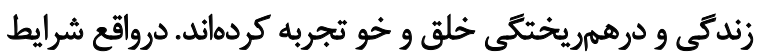

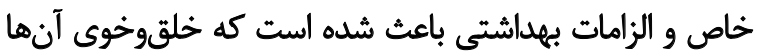

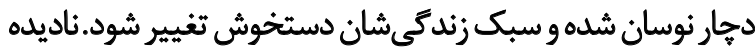

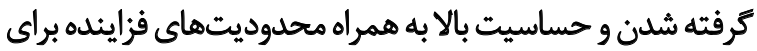

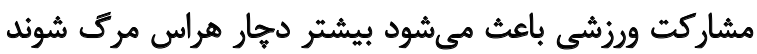

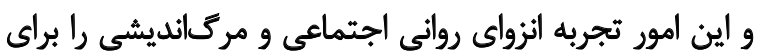

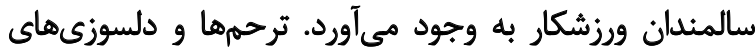

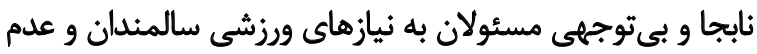

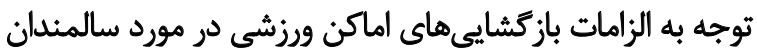

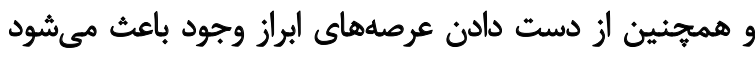

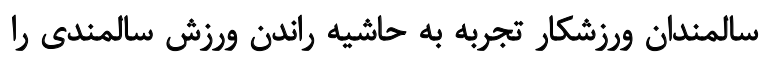

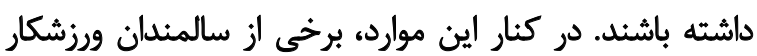

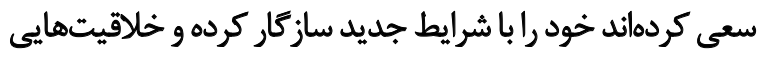

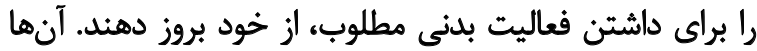

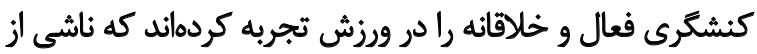

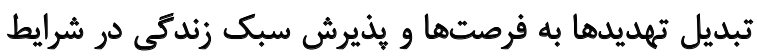
همليرى كوويد 19 است.

بر اساس نتايج تحقيق مىتوان اينكونه بيان كرد كه ماحصل
ورزشى براي سالمندان به شيواى نابرابر از ساير اقشار جامعه

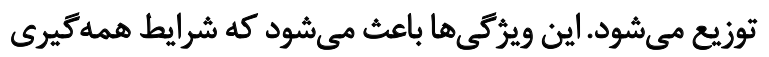

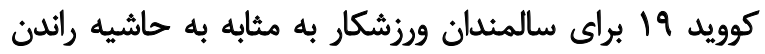

$$
\text { ورزش سالمندي تجريه شود. }
$$

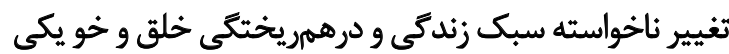

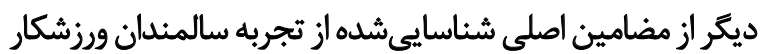

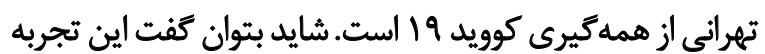

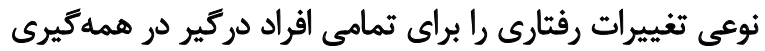

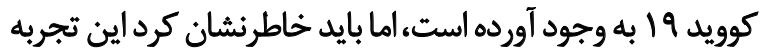

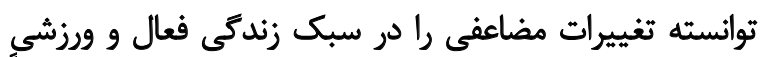

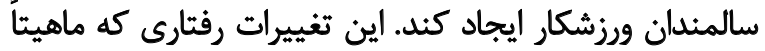

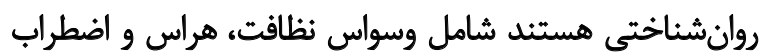

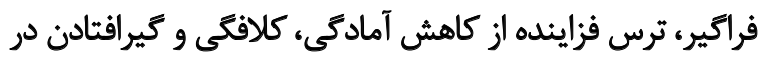

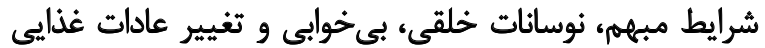

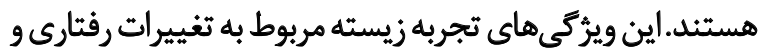

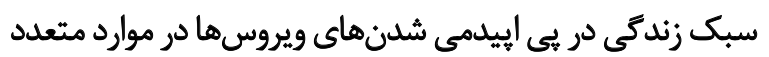

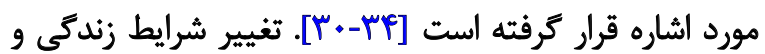

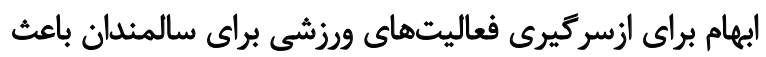

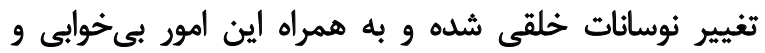

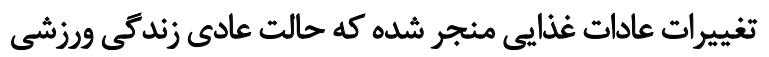

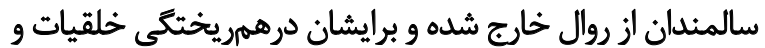

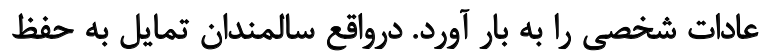

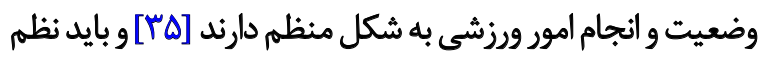

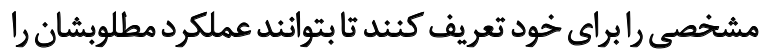

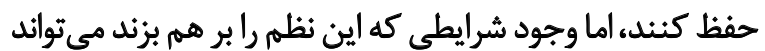

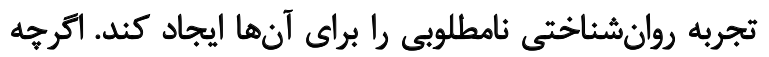

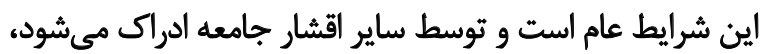

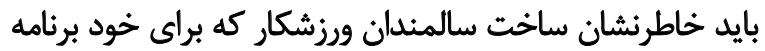

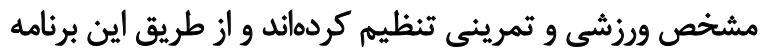

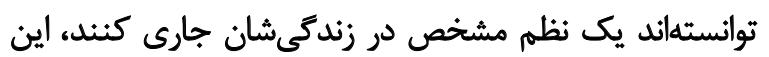

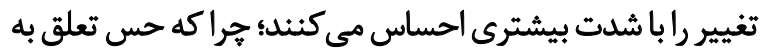

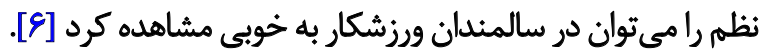

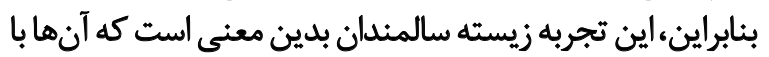

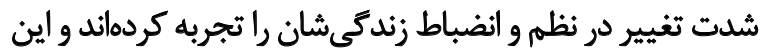

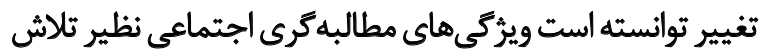
براى از حاشيه درآوردن ورزش سالمندى را تشديد كند. آخرين مضمون اصلى كشفشده كنشكرى فعال و خلاقاثه

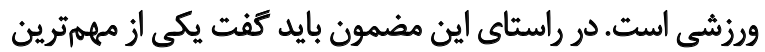

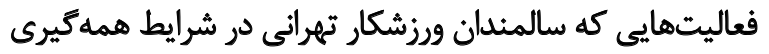

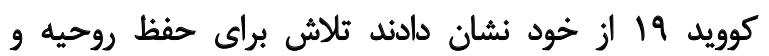

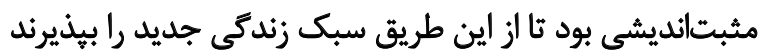

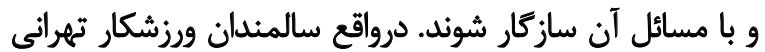

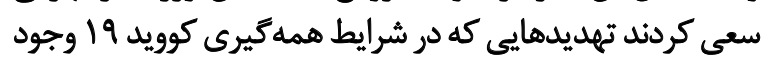

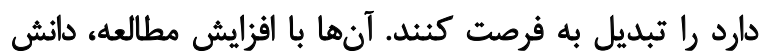


سالمندان فرم رضايت أكاهانه جهت شركت در مطالعه را امضا

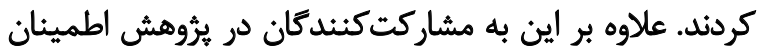

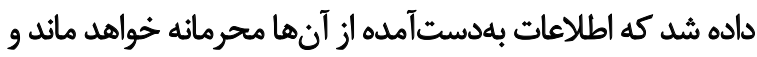

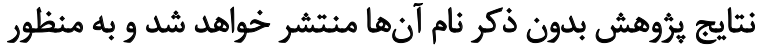

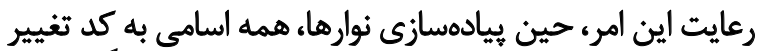

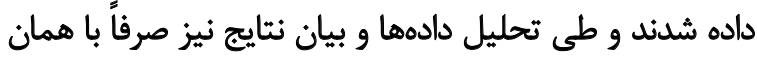

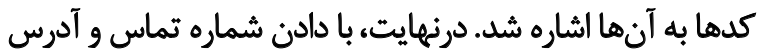

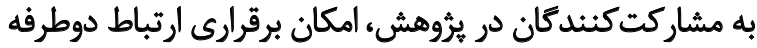

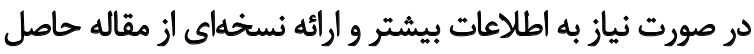

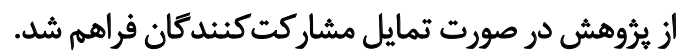

$$
\text { مامي مالبي }
$$

اين مقاله مستخرج از برورةه تحقيقى مستقل عضو هيئتعلمى

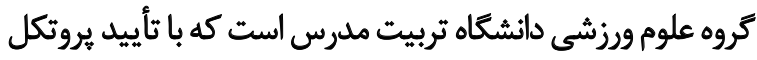

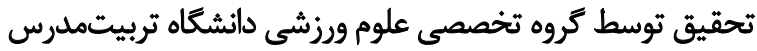

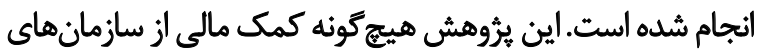

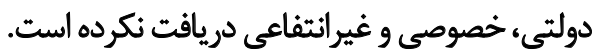

$$
\text { مشاركت نويسند مَان }
$$

همه نويسندكان به يك اندازه در نكارش مقاله مشاركت

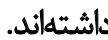

$$
\text { ت تعارض مناقع }
$$

بنابر اظهار نويسندكان اين مقاله تعارض منافع ندارد.
نظرى اين تحقيق شناخت بهتر متصديان و مسئولان مديريت

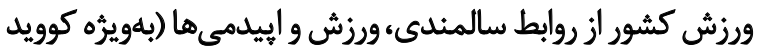

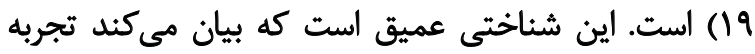

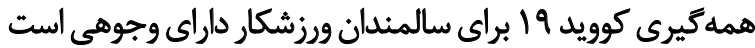
كه مى توانند در دو دسته مثبت و و مندي

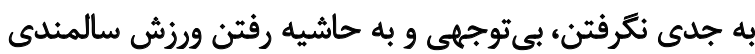

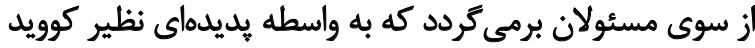

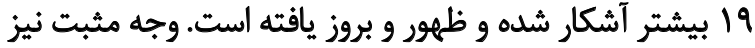

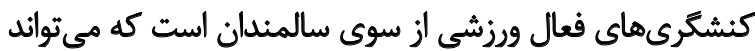

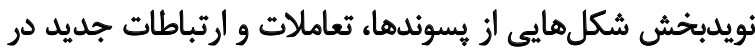

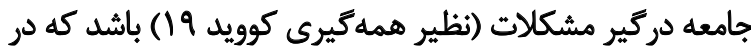

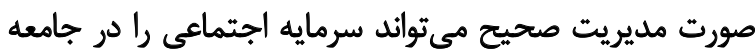

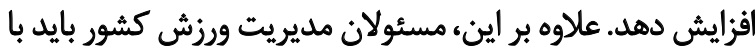

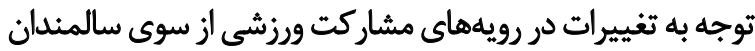

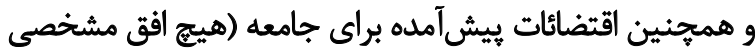

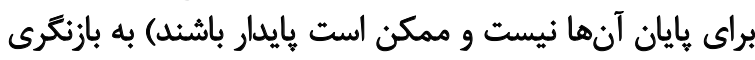

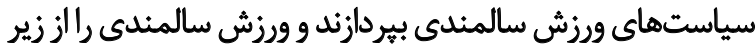

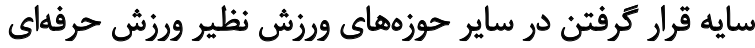

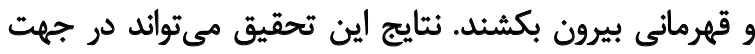

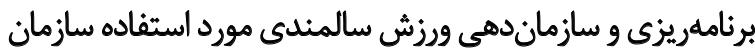
ورزش شهردارى تهران قرار كيرد. درنهايت بايد ذكر شود كه اين بثروهش به روش كيفى انجام

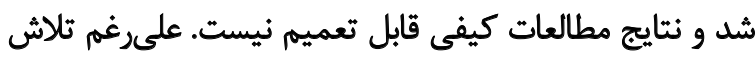

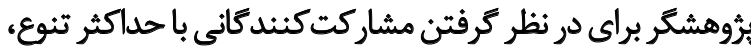

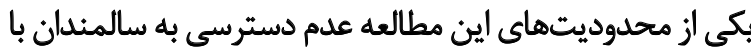

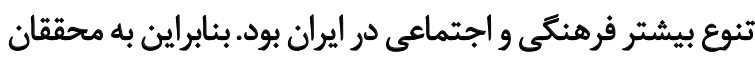

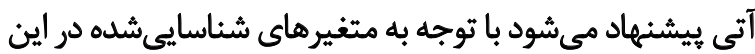

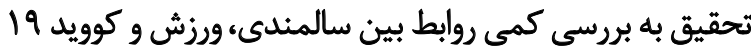

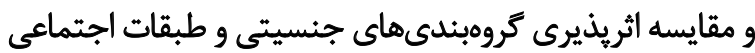
سالمندان ورزشكار از همدكيرى كوويد 19 ايرداخته شودي

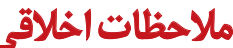

\section{بيروى أز اصول اخلاق بثوهش}

روند اجراي اين مطالعه در كميته تخصصى گروه علوم ورزشى

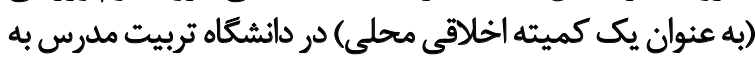

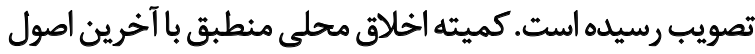

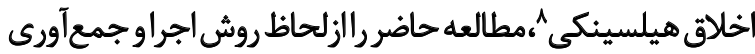

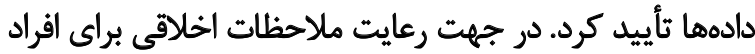

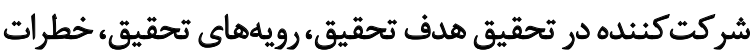

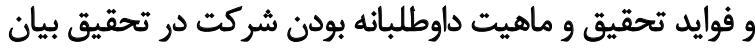

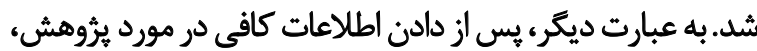

8. Declaration of Helsinki 


\section{Reference}

[1] Sadeghmoghadam L, Foroughan M, Mohammadi Shahboulaghi F, Ahmadi F, Nazari S, Farhadi A, et al. [The lived experiences of aging in older adults: A phenomenological study (Persian)]. Iranian Journal of Ageing. 2020; 14(4):478-93. [doi: 10.32598/sija.13.10.400]

[2] Stewart AL, King AC. Evaluating the efficacy of physical activity for influencing quality-of-life outcomes in older adults. Annals of Behavioral Medicine. 1991; 13(3):108-16. [DOI:10.1093/ $\mathrm{abm} / 13.3 .108]$

[3] Lee TW, Ko IS, Lee KJ. Health promotion behaviors and quality of life among community-dwelling elderly in Korea: A crosssectional survey. International Journal of Nursing Studies. 2006; 43(3):293-300. [DOI:10.1016/j.ijnurstu.2005.06.009] [PMID]

[4] Lord SR, Castell S. Physical activity program for older persons: Effect on balance, strength, neuromuscular control, and reaction time. Archives of Physical Medicine and Rehabilitation. 1994; 75(6):648-52. [DOI:10.1016/0003-9993(94)90187-2]

[5] Edwards A, Skinner J. Qualitative research in sport management. United Kingdom: Routledge; 2010. https:/ / books.google. com/books/about/Qualitative_Research_in_Sport_Management.html?id=PBc-eUYmfD4C

[6] Ishizaki T, Kai I, Kobayashi Y, Imanaka Y. Functional transitions and active life expectancy for older Japanese living in a community. Archives of Gerontology and Geriatrics. 2002; 35(2):107-20. [DOI:10.1016/S0167-4943(02)00002-X]

[7] Mavrovouniotis FH, Argiriadou EA, Papaioannou CS. Greek traditional dances and quality of old people's life. Journal of Bodywork and Movement Therapies. 2010; 14(3):209-18. [DOI:10.1016/j.jbmt.2008.11.005] [PMID]

[8] Ross KM, Milsom VA, Rickel KA, DeBraganza N, Gibbons LM, Murawski ME, et al. The contributions of weight loss and increased physical fitness to improvements in health-related quality of life. Eating Behaviors. 2009; 10(2):84-8. [DOI:10.1016/j. eatbeh.2008.12.002] [PMID] [PMCID]

[9] Sadati AK, Lankarani MHB, Lankarani KB. Risk society, global vulnerability and fragile resilience; Sociological view on the coronavirus outbreak. Shiraz E-Medical Journal. 2020; 21(4):e102263. [DOI:10.5812/semj.102263]

[10] Nieß A, Bloch W, Friedmann-Bette B, Grim C, Halle M, Hirschmüller A, et al. Positionspapier" Return to Sport" während der aktuellen Coronavirus-Pandemie (SARS-CoV-2/COVID-19). Dtsch Z Sportmed. 2020; 71:E1-4. [DOI:10.5960/dzsm.2020.437]

[11] Bults M, Beaujean DJ, Richardus JH, Voeten HA. Perceptions and behavioral responses of the general public during the 2009 influenza A (H1N1) pandemic: A systematic review. Disaster Medicine and Public Health Preparedness, 2015; 9(2):207-19. [DOI:10.1017/dmp.2014.160] [PMID]

[12] Mann RH, Clift BC, Boykoff J, Bekker S. Athletes as community; Athletes in community: Covid-19, sporting mega-events and athlete health protection. British Journal of Sports Medicine. 2020; 54(18):1071-2. [DOI:10.1136/bjsports-2020-102433] [PMID] [PMCID]

[13] Hull JH, Loosemore M, Schwellnus M. Respiratory health in athletes: facing the COVID-19 challenge. The Lancet Respiratory Medicine. 2020; 8(6):557-8. [DOI:10.1016/S2213-2600(20)30175-2]
[14] Baggish A, Drezner JA, Kim J, Martinez M, Prutkin JM. Resurgence of sport in the wake of COVID-19: Cardiac considerations in competitive athletes. British Journal of Sports Medicine. 2020; 54(19):1130-1. [DOI:10.1136/bjsports-2020-102516] [PMID] [PMCID]

[15] Sarto F, Impellizzeri FM, Spörri J, Porcelli S, Olmo J, Requena B, et al. Impact of potential physiological changes due to COVID-19 home confinement on athlete health protection in elite sports: A call for awareness in sports programming. Sports Medicine (Auckland, Nz). 2020; 50(8):1417-9. [DOI:10.31236/osf.io/4zb3a]

[16] Kim ACH, Ryu J, Lee C, Kim KM, Heo J.Sport participation and happiness among older adults: A mediating role of social capital. Journal of Happiness Studies. 2020; 22:1623-41. [DOI:10.1007/ s10902-020-00288-8]

[17] Evans AB, Blackwell J, Dolan P, Fahlén J, Hoekman R, Lenneis $\mathrm{V}$, et al. Sport in the face of the COVID-19 pandemic: Towards an agenda for research in the sociology of sport. European Journal for Sport and Society. 2020; 17(2):85-95. [DOI:10.1080/16138171 2020.1765100]

[18] Patton MQ. Qualitative evaluation and research methods. $2^{\text {th }}$ ed. California; SAGE Publications, inc; 1990. https:/ / psycnet.apa org/record/1990-97369-000

[19] Nieswiadomy RM, Bailey C. Foundations of nursing research. $7^{\text {th }}$ ed. London: Pearson; 2017. https://www.amazon. com/Foundations-Nursing-Research-Marie-Nieswiadomy/ $\mathrm{dp} / 013416721 X$

[20] Danaeefard H, Kazemi H. Interpretive research in organizations: Phenomenology and phenomenography Strategies. Tehran: ISU press; 2012.

[21] Diekelmann NL. Behavioral pedagogy: A Heideggerian hermeneutical analysis of the lived experiences of students and teachers in baccalaureate nursing education. Journal of Nursing Education 1993; 32(6):245-250. [DOI:10.3928/0148-4834-19930601-04]

[22] Holloway I, Wheeler S. Qualitative research for nurses. New Jersey: Wiley; 1996. https://books.google. com/books/about/Qualitative_Research_for_Nurses $\mathrm{html}$ ?id=WDuVQgAACAAJ\&source=kp_book_description

[23] Denzin NK, Lincoln YS. Handbook of qualitative research. California: Sage; 1994. https://www.worldcat.org/title/handbookof-qualitative-research/oclc/29029458

[24] Giorgi A. An application of phenomenological method in psychology. Duquesne Studies in Phenomenological Psychology. 1975; 2:82-103. [DOI:10.5840/dspp197529]

[25] Kleynhans J, Treurnicht FK, Cohen C, Vedan T, Seleka M, Maki L, et al. Outbreak of influenza A in a boarding school in South Africa, 2016. The Pan African Medical Journal. 2019; 33:42. [DOI:10.11604/pami.2019.33.42.16666] [PMID] [PMCID]

[26] Kessler RC, McGonagle KA, Zhao S, Nelson CB, Hughes M, Eshleman S, et al. Lifetime and 12-month prevalence of DSM-III-R psychiatric disorders in the United States: Results from the National Comorbidity Survey. Archives of General Psychiatry 1994 51(1):8-19. [DOI:10.1001/archpsyc.1994.03950010008002] [PMID]

[27] Jones JH, Salathe M. Early assessment of anxiety and behavioral response to novel swine-origin influenza A (H1N1). PLoS One. 2009; 4(12):e8032. [DOI:10.1371/journal.pone.0008032] [PMID] [PMCID] 
[28] Popham F, Mitchell R. Leisure time exercise and personal circumstances in the working age population: Longitudinal analysis of the British household panel survey. Journal of Epidemiology \& Community Health. 2006; 60(3):270-4. [DOI:10.1136/ jech.2005.041194] [PMID] [PMCID]

[29] Walsh DW, Green BC, Holahan C, Cance JD, Lee D. Healthy aging? An evaluation of sport participation as a resource for older adults in retirement. Journal of Leisure Research. 2019; 50(1):56-80. [DOI:10.1080/00222216.2018.1554092]

[30] Yeung NC, Lau JT, Choi KC, Griffiths S. Population responses during the pandemic phase of the influenza A (H1N1) pdm09 Epidemic, Hong Kong, China. Emerging Infectious Diseases. 2017; 23(5):813-5. [DOI:10.3201/eid2305.160768] [PMID] [PMCID]

[31] Starcevic V, Portman ME, Beck AT. Generalized anxiety disorder: between neglect and an epidemic. The Journal of Nervous and Mental Disease. 2012; 200(8):664-7. [DOI:10.1097/ NMD.0b013e318263f947] [PMID]

[32] Handcock MS, Jones JH. Likelihood-based inference for stochastic models of sexual network formation. Theoretical Population Biology. 2004; 65(4):413-22. [DOI:10.1016/j.tpb.2003.09.006] [PMID]

[33] Baxter AJ, Scott KM, Ferrari AJ, Norman RE, Vos T, Whiteford HA. Challenging the myth of an "epidemic" of common mental disorders: Trends in the global prevalence of anxiety and depression between 1990 and 2010. Depression and Anxiety. 2014; 31(6):506-16. [DOI:10.1002/da.22230] [PMID]

[34] Richter D, Berger K. [Are mental disorders increasing? Update of a systematic review on repeated cross-sectional studies (German)]. Psychiatr Prax. 2013; 40(4):176-82. [DOI:10.1055/s-0032-1333060] [PMID]

[35] Göksu ÖC, Yüksek S, Ayan V, Güler MŞ. The importance of sport in aging process. Journal of Education and Training Studies. 2019; 7(9):22-31. [DOI:10.11114/jets.v7i9.4350]

[36] Lanagan J, Smeaton AF. Using Twitter to detect and tag important events in sports media. Proceedings of the Fifth International AAAI Conference on Weblogs and Social Media. 2011; 5(1):542-5. https://ojs.aaai.org/index.php/ICWSM/article/view/14170 
This Page Intentionally Left Blank 